\title{
همايير الأسلوب القصصي في السنة النبوية
}

Standards of narrative style in the Prophet's Sunnah

\author{
إعداد \\ هيراج جاء ديراج \\ Mirage Gad Siraj \\ المركز الإسلامي - الهند
}

Doi: 10.21608/jnal.2021.184532

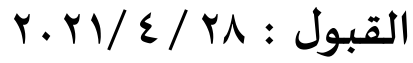

الاستام:

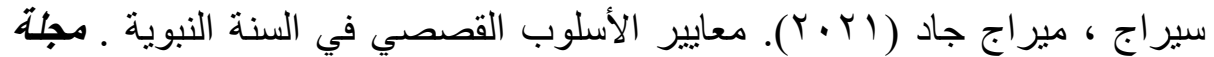

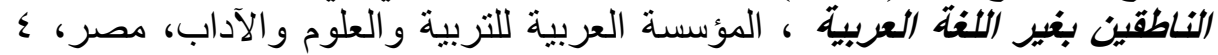
. 


\section{معايير الأسلوب القصصي في السنة النبوية}

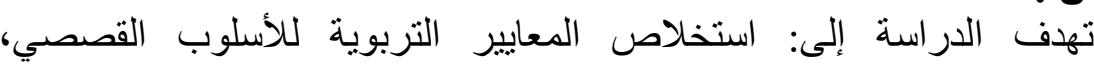

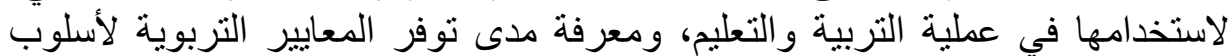

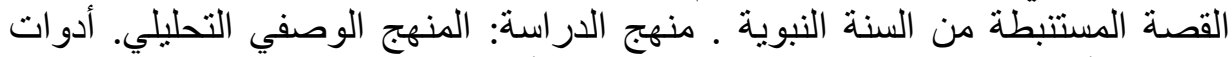

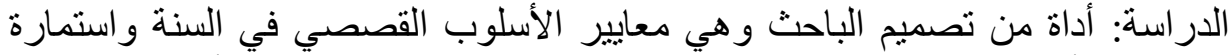

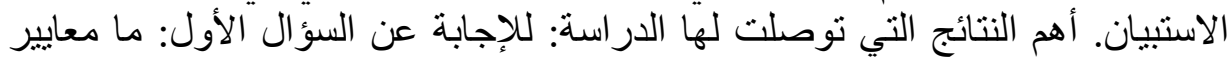

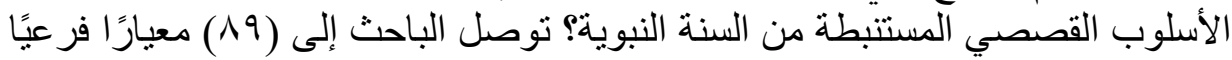
تندر ج تحت (• (1) معايير رئيسية. الكلمات المفتاحية: المعايير التربوية، القصة النبوية، الأسلوب القصصي.

\section{Abstract}

Teaching Islamic Education course in light of the criteria of the narrative method in the prophetic tradition in the basic education phase; seventh, eighth, and ninth grades in Syria. Goals:1. Identifying the educational criteria of the narrative method in order to be used in the process of education.2. Having knowledge of to what extent the teachers of Islamic Education have the story-based educational criteria for the preparatory stage in Aleppo governorate in Syria.Methodology: The descriptive analytical approach.Tools: A tool of the researcher's design; the criteria of the narrative method of the prophetic Sunnah, and a questionnaire form.Outcomes:To answer the first question: what are the criteria of the narrative method derived from the prophetic Sunnah? The researcher reached the (89) sub-criteria that fall under (10) Key criteria.To answer the second question. 
إنَّ التربية الإسلامية سباقة لاستخدامها كثيراً من الطرق والوسائل التربوية

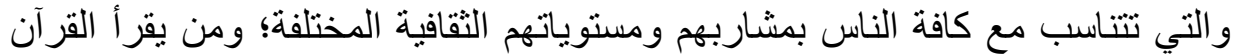

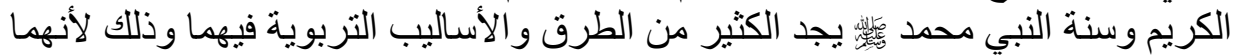

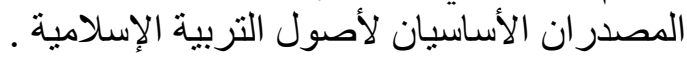

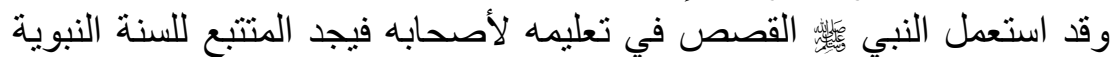

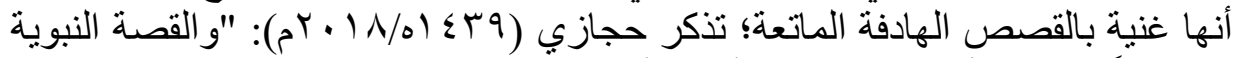

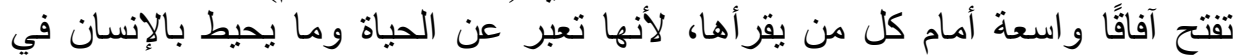

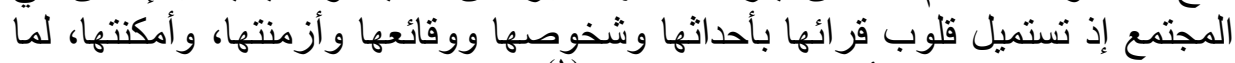

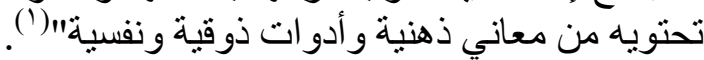

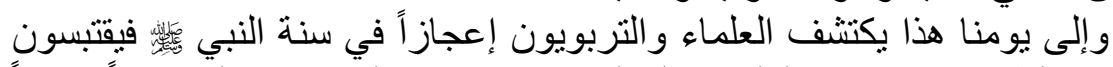

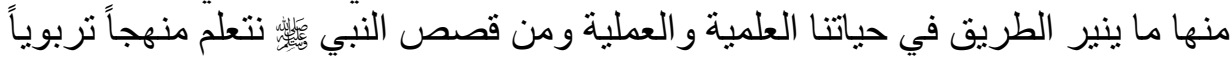

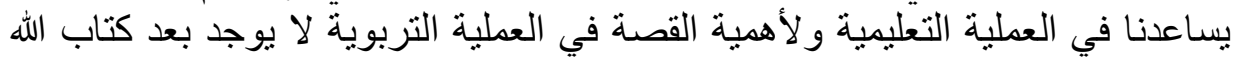

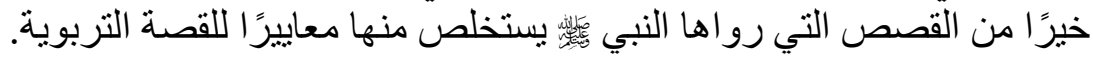

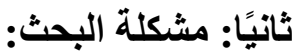

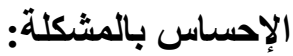

يرى الباحث ضرورة دراسة القصص النصان النبوي والاستفادة من المعايير التربوية

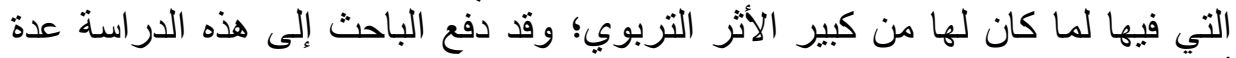

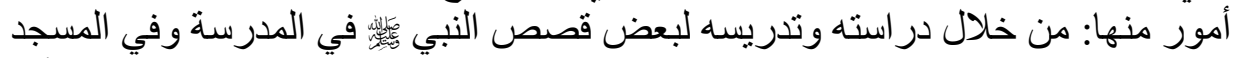

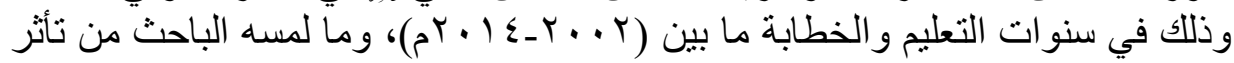

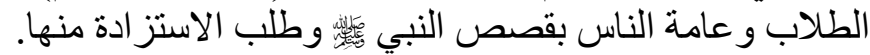

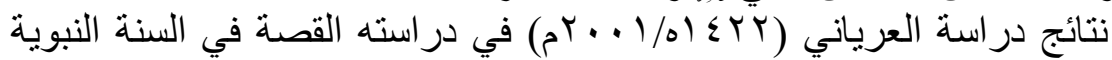

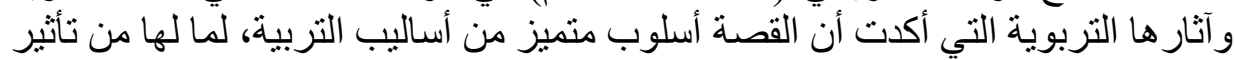

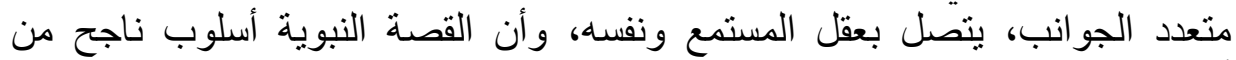

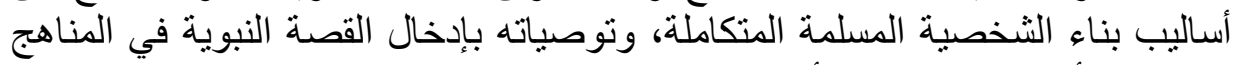
التعليمية كأسلوب فريد من الأساليب التربوية التي تسهم في بناء المتعلمين بناءً إسلاميًا

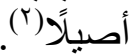

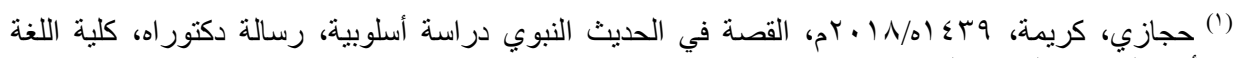

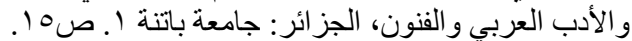

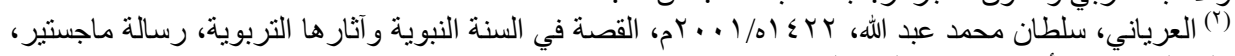

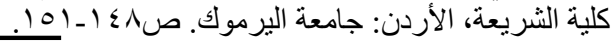




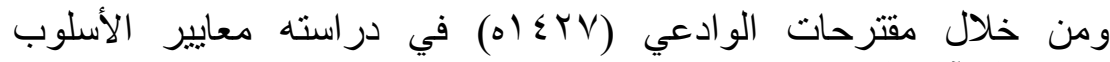

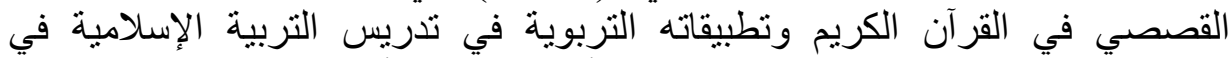

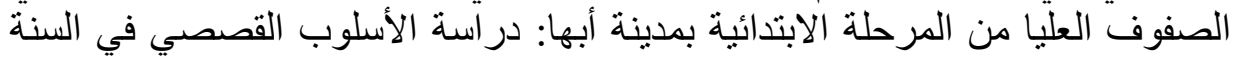

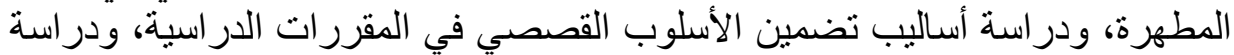

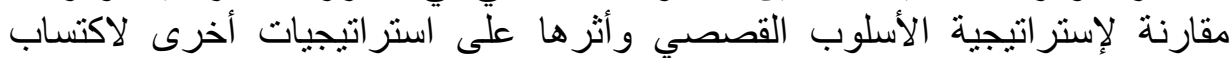

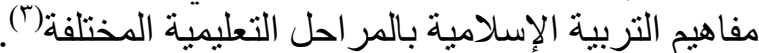

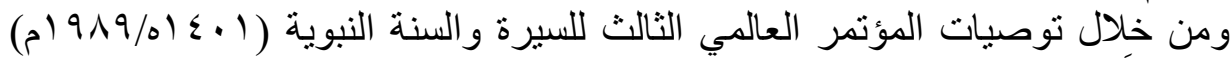

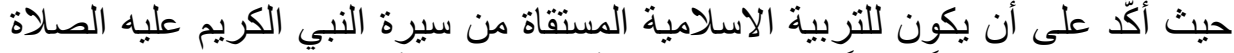

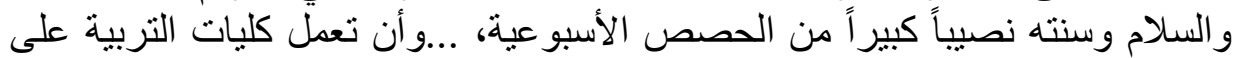

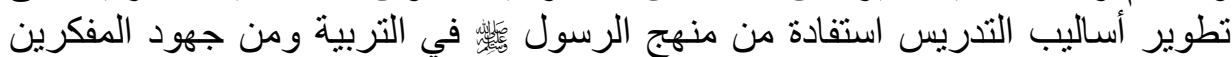

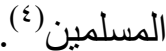

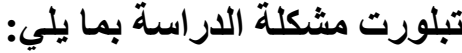

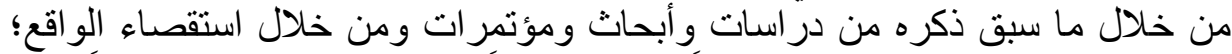

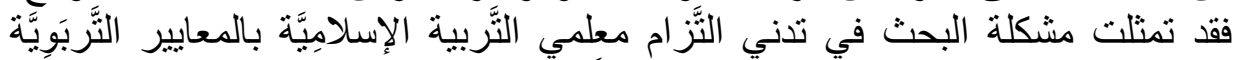

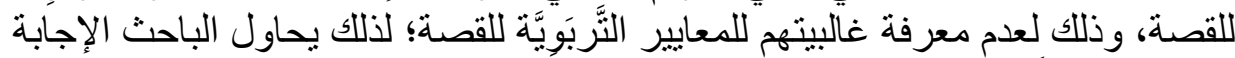

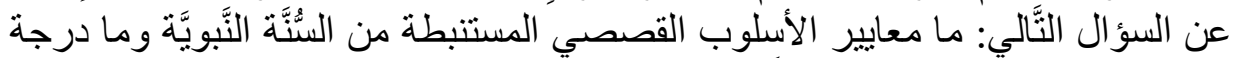

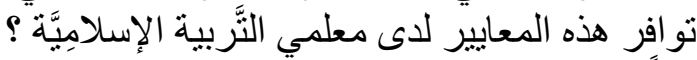

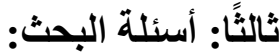
تتبلور أسئلة البحث في البحث: السؤ الين التَّليين:

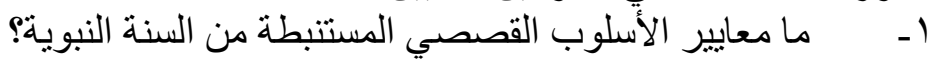

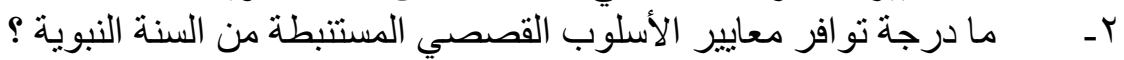

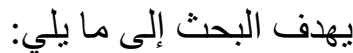

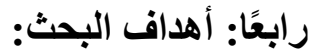
1- التعرف على المعايير التربوية للأسلوب القصصي، لاستخدامها في عملية

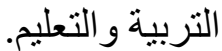
r- معرفة مدى تو افر المعايير التربوية لأسلوب القصة المستنبطة من السنة النبوية

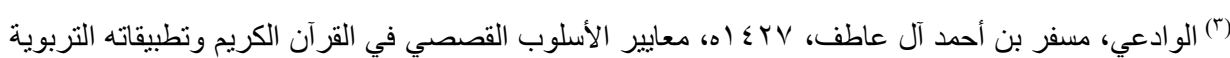
في تدريس التربية الإسلامية في الصفوف العليا من المرحلة الابتدائية بمدينة أبها، رسالة ماجستير ، كلية التربية،

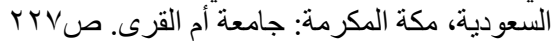

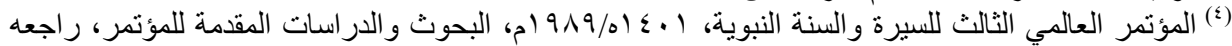

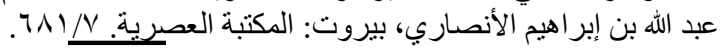


ترجع أهميَّة البحث إلى جانبين و هما جانب نظري وجانب تطبيقي:

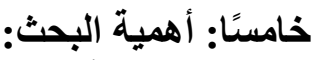

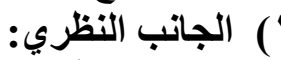

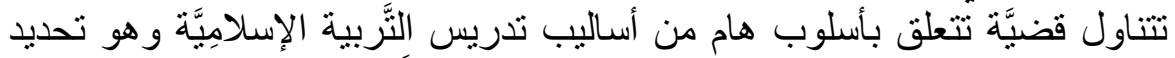

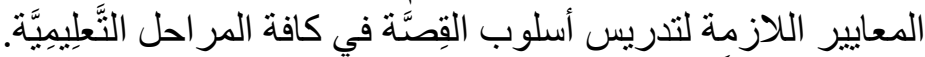

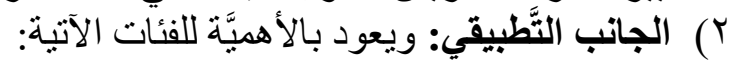

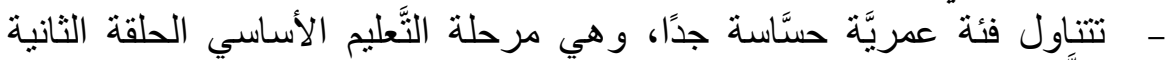

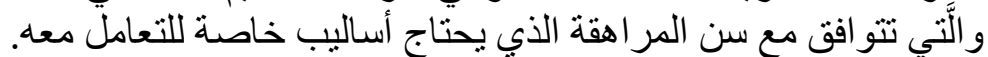

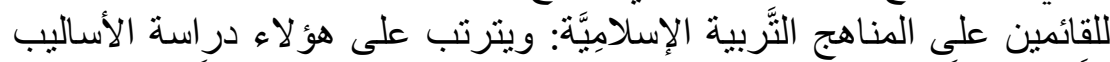

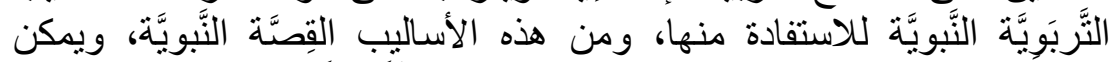

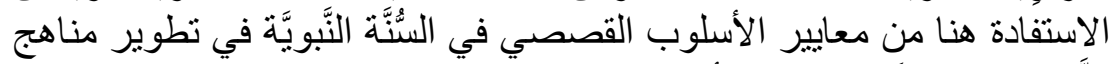

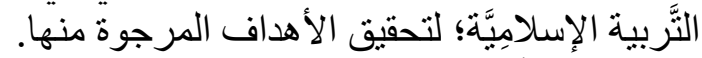

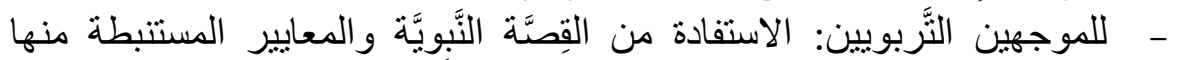

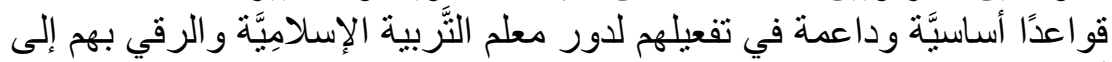
أفضل المستويات.

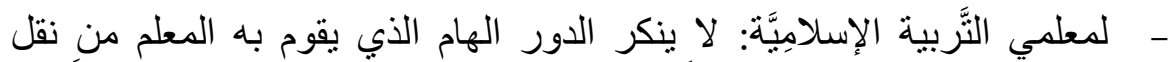

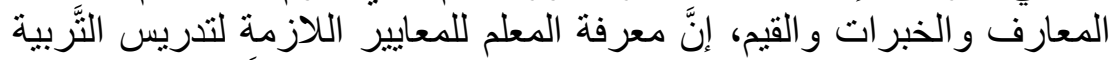

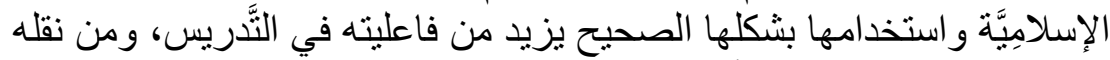

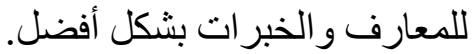
- للمتعلمين: تحقق لهم الفائدة من القصص التصل النبوي لمعرفة ما فيها من معارف وخبرات وقيم.

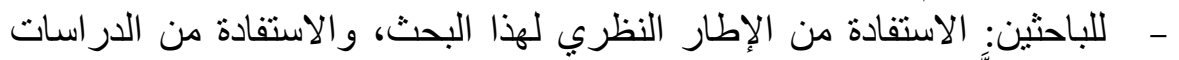

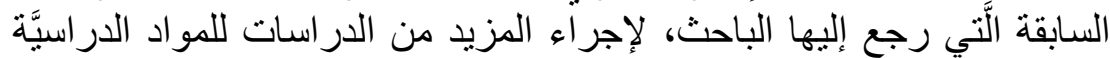

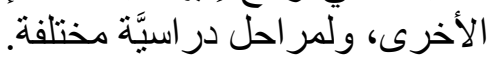

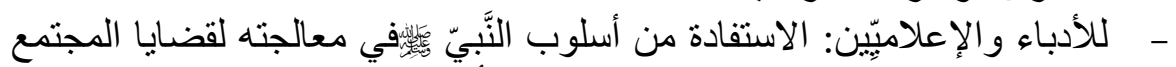

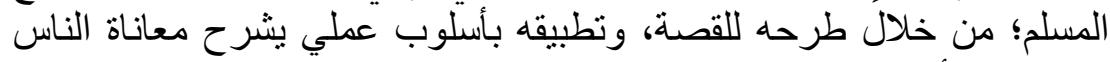

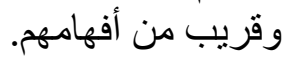
سادسًا: حدود البحث:

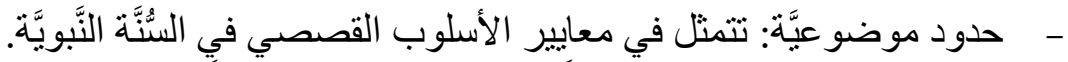

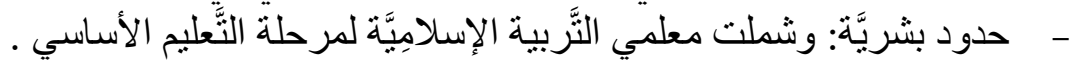




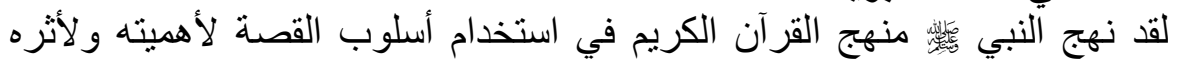

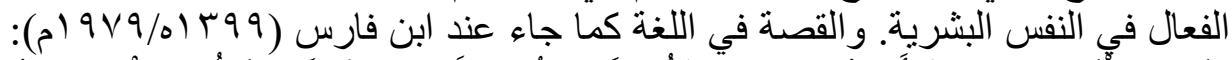

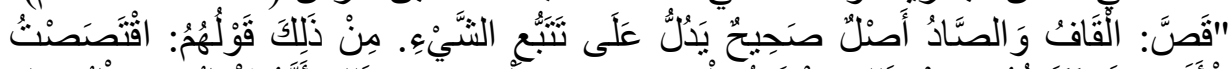

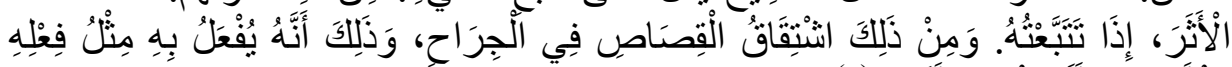

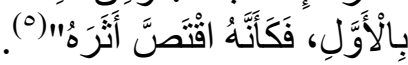
و القصة النبوية أحداث تصور الحباة، وهي مفسرة لما جاء في القرآن الكريم

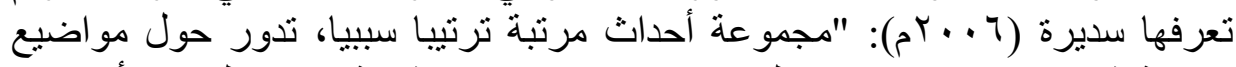

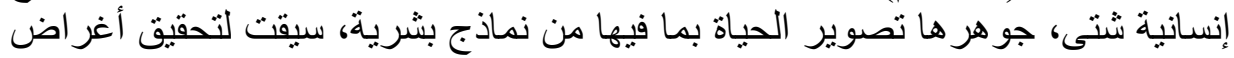

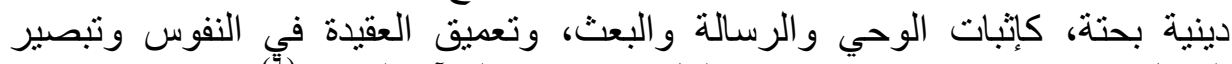

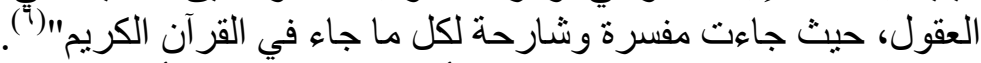

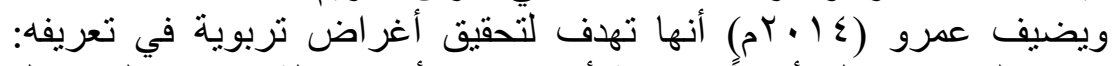
"أسلوب نبوي بليغ يروي لنا أحداثًا ماضية أو أو حاضرة أو مستقبلة، سواء على سلى سبيل

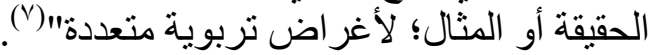

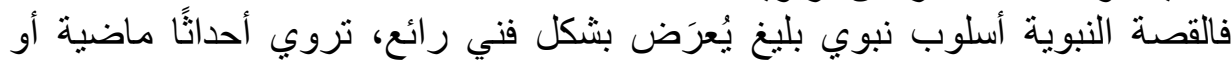

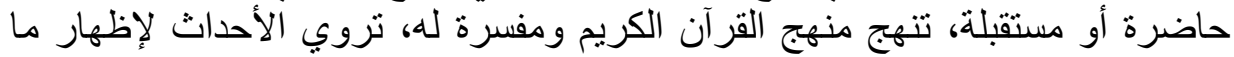
فيها من نتائج و عبر و عظاتك، تهوف إلى غرس القيم الدينية في نفوس المؤمنين وتثيبيتها، تسعى لتحقيق أهداف و وغايات تربوية.

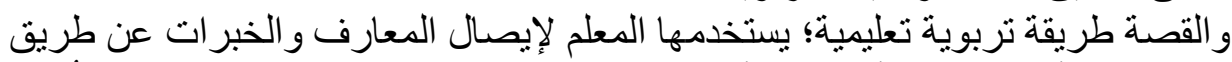

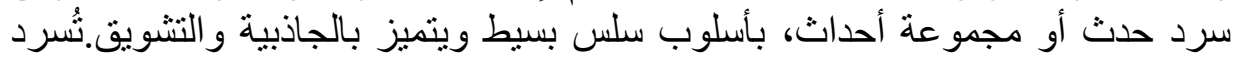

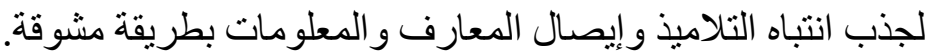

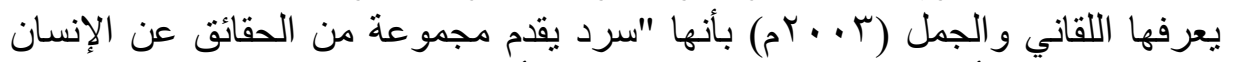

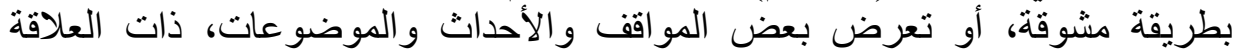
بشخصيات متعددة، وأنو اعها متعددة، منها القصة التاريخية، و القصة الو اقعية، والقصة القصة

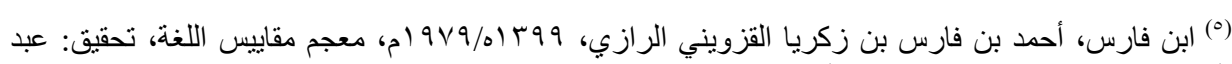

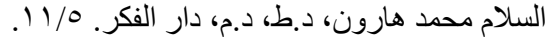

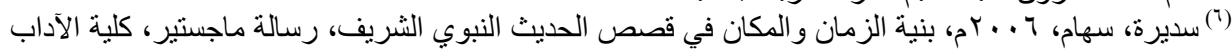

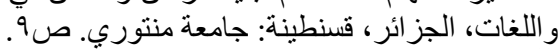

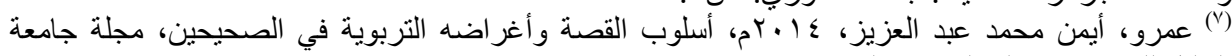

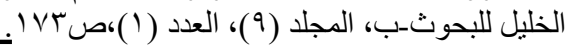


التمثلية، وتعد أحد الأساليب المهمة في عملية التعلم، حيث تساعد على جذب انتباه

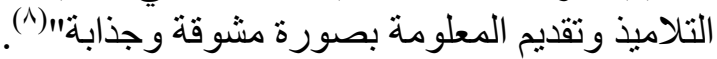

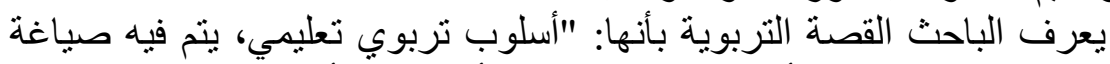

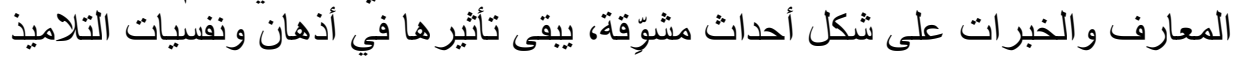
للمدة طويلة من الزمن.

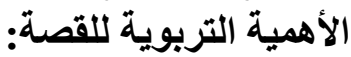

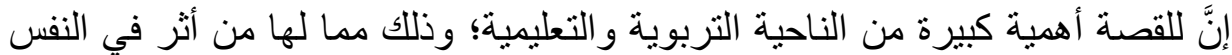

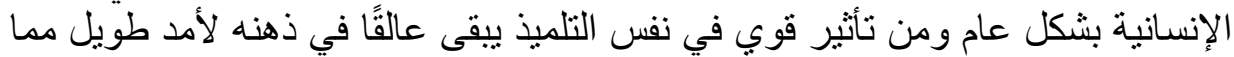

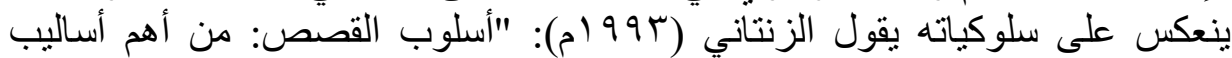

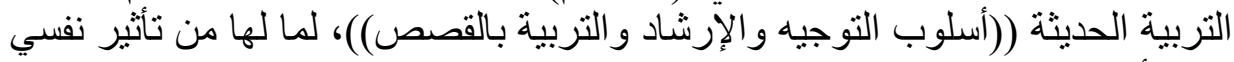

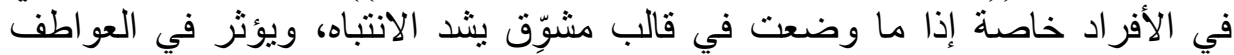

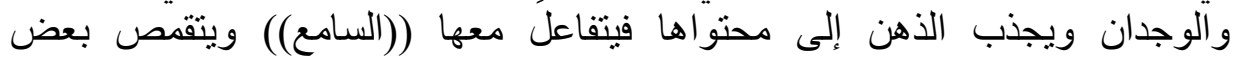

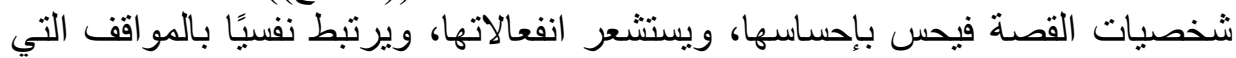

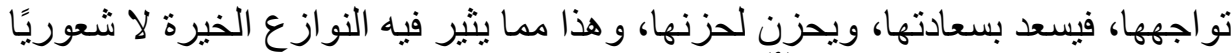

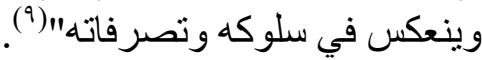

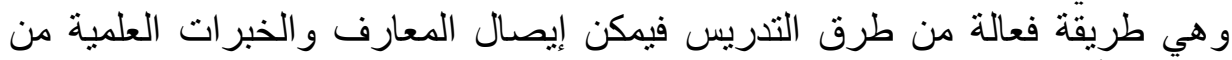

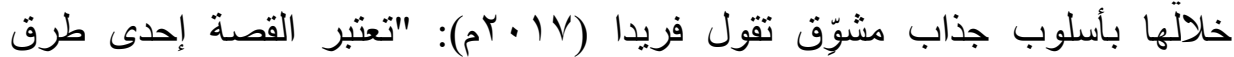

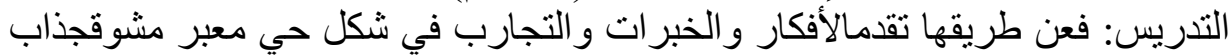

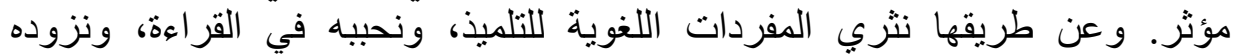

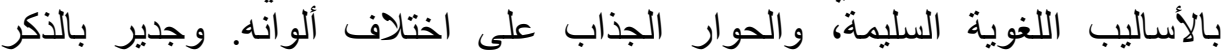

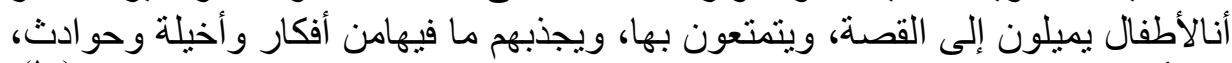

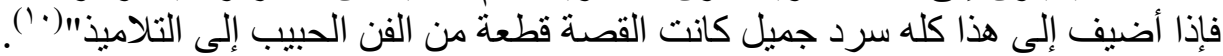

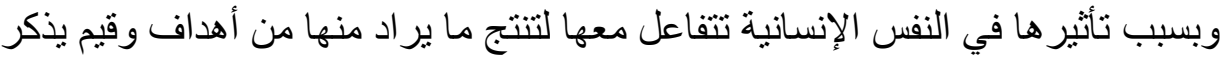

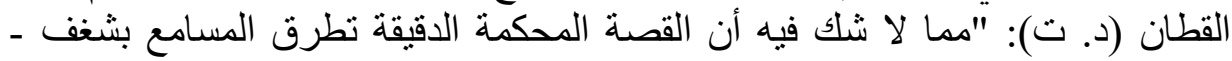

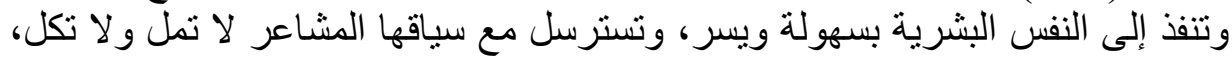
ويرتاد العقل عناصر ها فيجني من حقولها الأز اهير والثمار . و الدروس التلقينية الثية الإلقائية

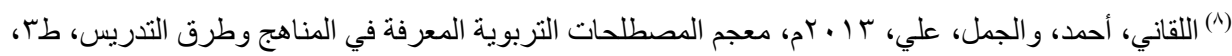
القاهرة: عالم الكتب. (9) الزنتاني، عبد الحميد الصبّيد، بو9 ام، أسس التربية الإسلامية في السنة النبوية، طץ، ليبيا: الدار العربية للكتاب.صل الزنتاني،

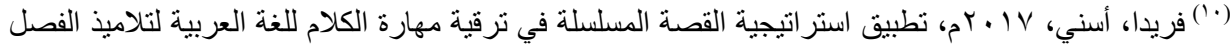

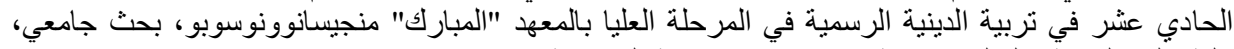

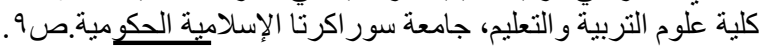


تورث الملل، و لا تستطيع الناشئة أن تتابعها وتستو عب عناصر ها إلا بصعوبة وشدة.

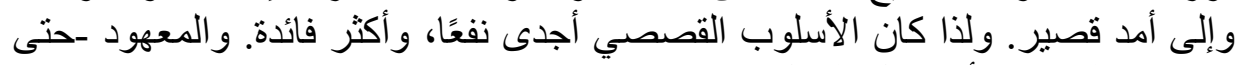

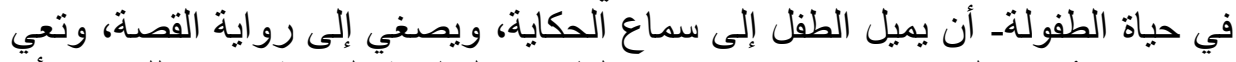

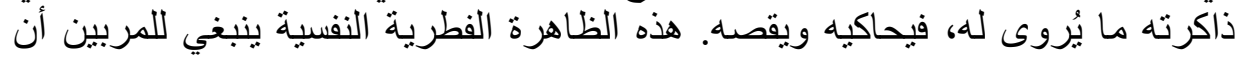

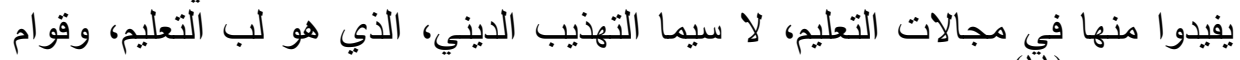

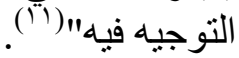

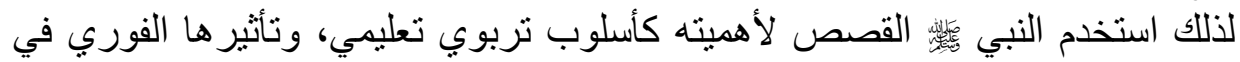

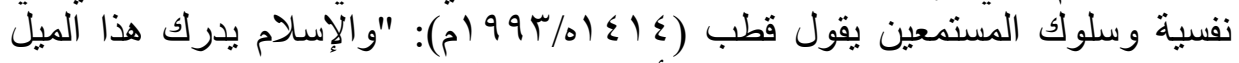

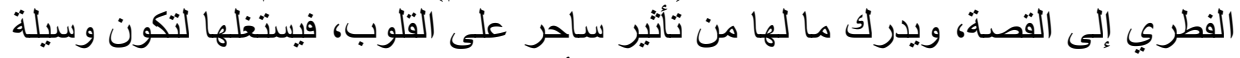

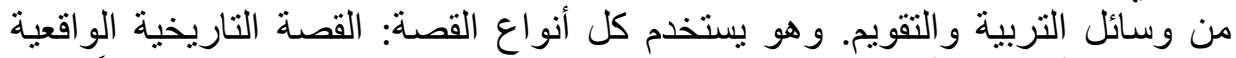

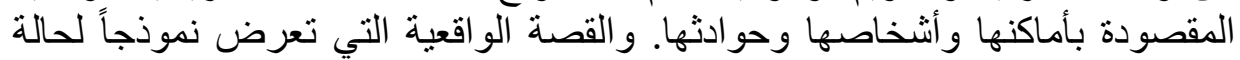

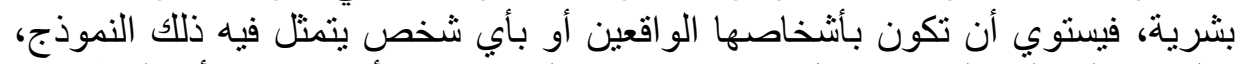

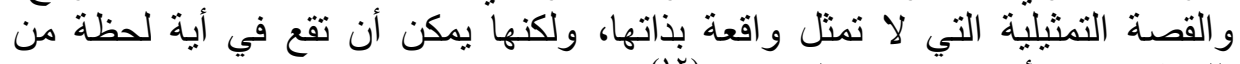

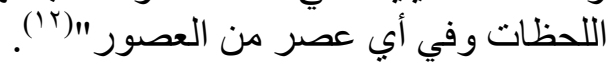

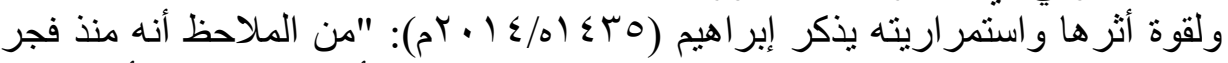

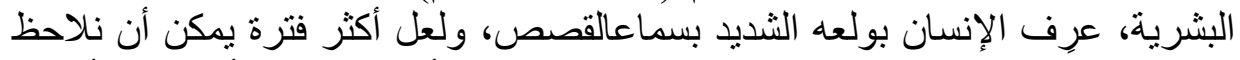

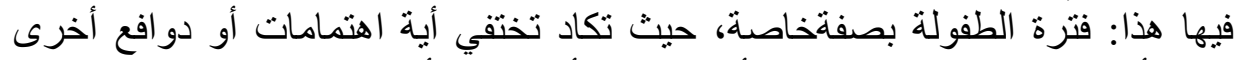

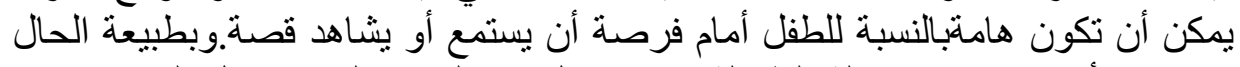

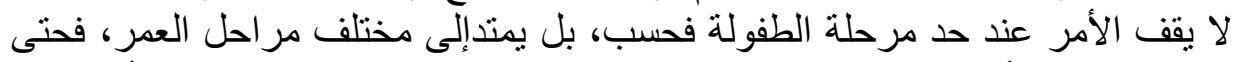

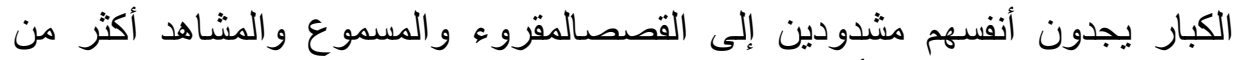

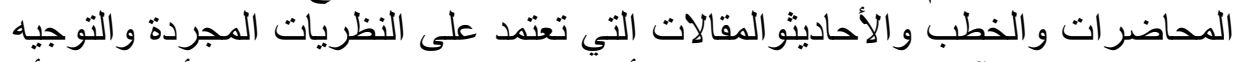

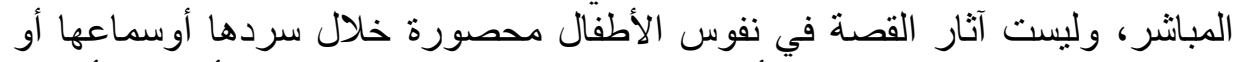

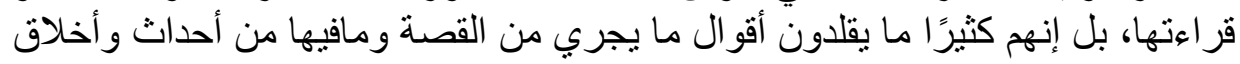

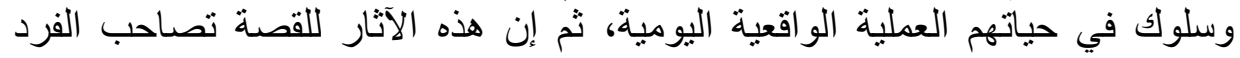

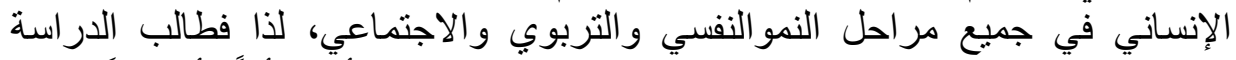

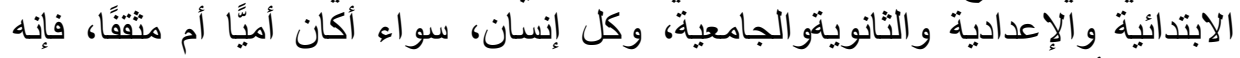

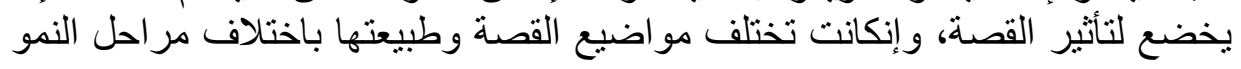


التكوينية،وباختلاف المستويات العقلية والاجتماعية والمزاجية، كما تختلف حسب

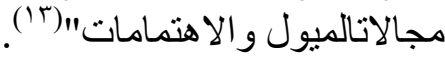
الأهداف التربوية للقصة:

الأهداف و الفوائد التي تحققها القصة الإسلامية و التربوية كثيرة جدًا ولكن يمكن إجمالها

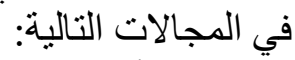

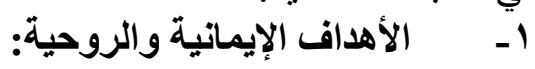

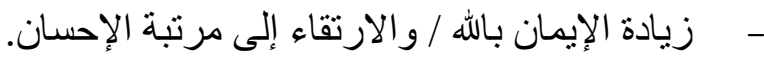

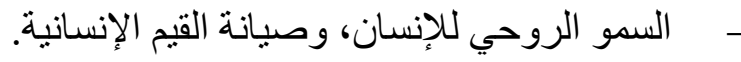
- ـ - ترسيخ مبادئ العقيدة الإسلامية الصحيحة.

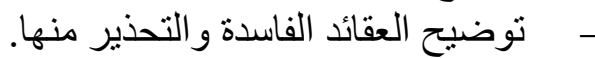
- - - تزويد الطلبة بالجو انب المناسبة من تصور الإسلام للكون و الإنسان و الحياة.

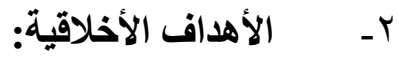

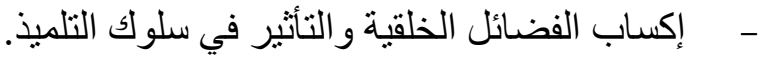
التنفير من الأخلاق و الصفات الصني السيئة. تزربية الجانب الفطري في الإنسان نحو النفات الخير.

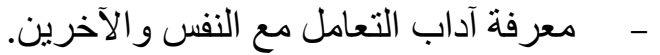
تحفيز السامع إلى الاعتبار و الاتعاظ.

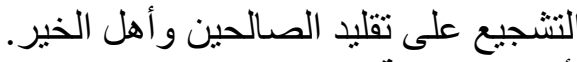

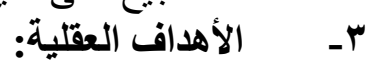
- متمية مهارة الانتباه ودقة الملاحظة وتذكر المو اقف و الأحداث و الأشخاص.

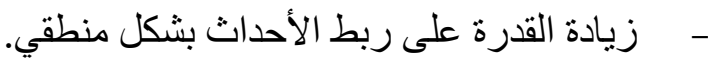

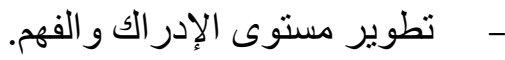
- - مكسب مهارة النقد و التحليل. -

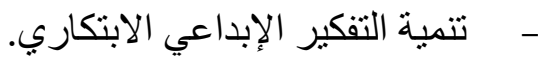

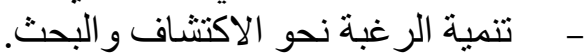

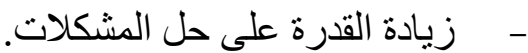
- - - - - - مساب أساليب التعليل و الاستنتاج.

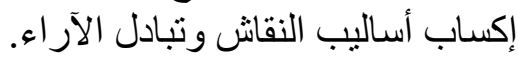

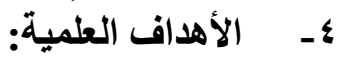


اكساب التلميذ كمَّا كبيرًا من المعارف و الخبرات.

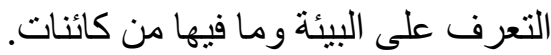
اكساب مفاهيم تاريخية وجغر الفية فئة الفية تساعد على تنمية القيم و الميول العلمية. تساعد على فهم أفضل و أعمق للمفاهيم العلمية. 0ـ الأهداف اللغوية: زيادة الثروة اللغوية عند التلميذ. تتمية مهارة التعبير وحسن صياغة لإنة الكلام. الرقي بالأسلوب اللغوي والنو و الكلامي. تتمية مهار ات القراعة والأبل الكتابة والاستماع. التشجيع على حب القر اءة و المطالعة.

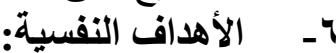
تعزيز الشعور بالطمأنينة وزيادة الثقة بالنفس.

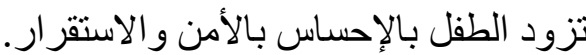

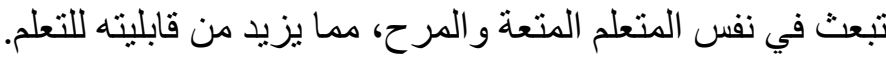

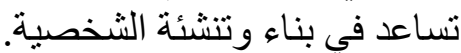
إثباع حاجات الطفل النفسية و المعرفية. - - - ألأهداف الاجتماعية: تربية الطفل على تحمل المسؤولية الفردية، التي تتمم المسؤولية في المجتمع.

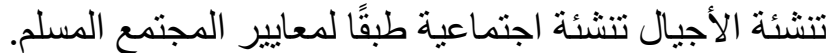

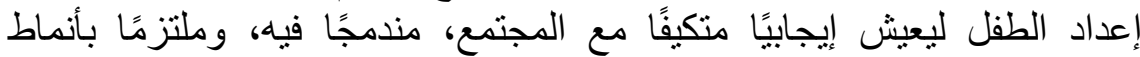
سلوكية إسلامية. تكوين علاقات اجتماعية ناجحة.

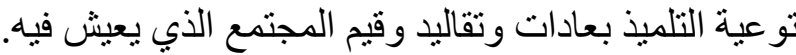

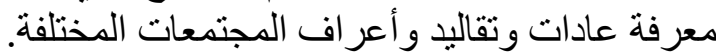

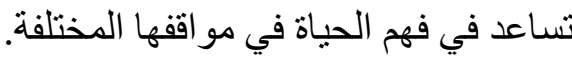
تنمية حب التعاون ومشاركة الآخرين.

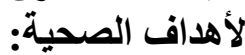

إكساب الطفل العادات الصحية الإسلامية السليمة.

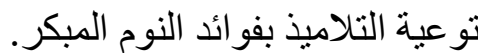
ذكر دور التغذية السليمة في صحة الجنمة التيكر. 
التشجيع على ممارسة الرياضة بانتظام. بيان أهمية العبادات في قوة الجسم. أهداف أخرى:

تو عية التلاميذ لأهمية المحافظة على البيئة.

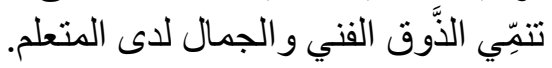

معالجة مشكلات الطفل الاجتماعية و النفسية والسلوكية.

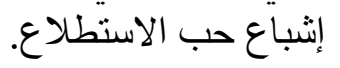

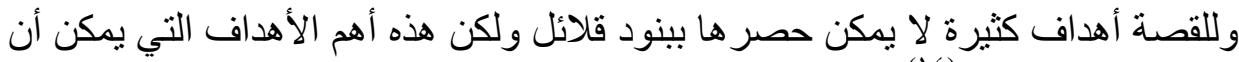

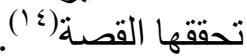

\section{معايير اختيار القصة للأطفال:}

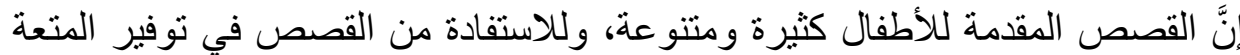

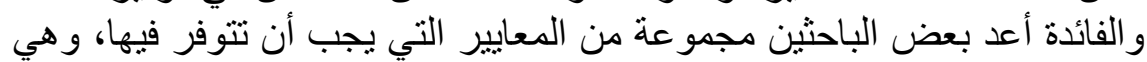

$$
\text { فيما يلي: }
$$

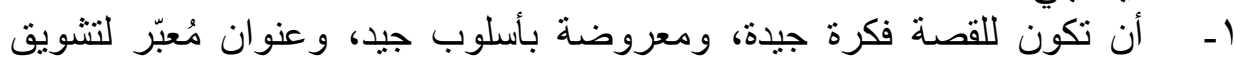

الطفل وجذبه إلى القصة النصة المقدمة ونة وامتاعه.

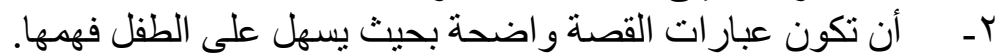

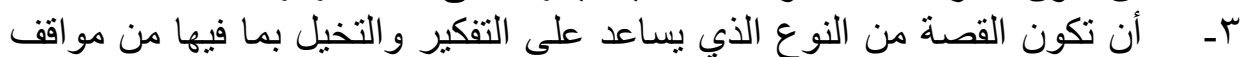

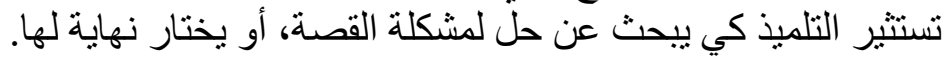

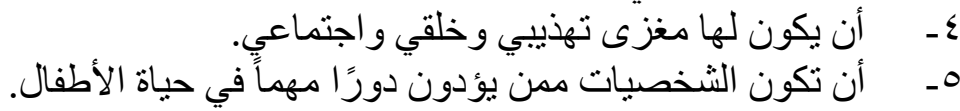

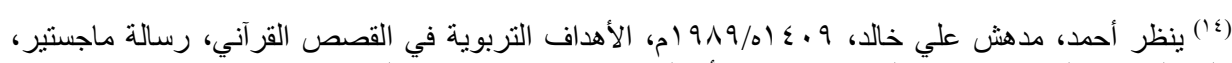

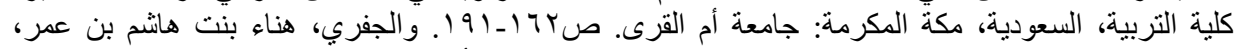

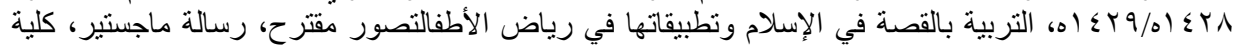

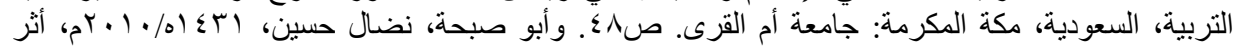

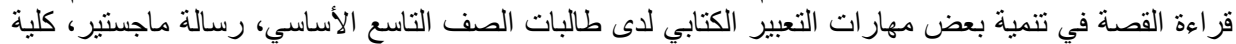

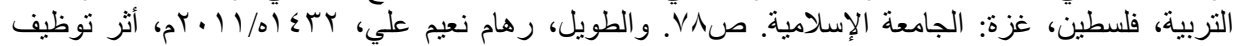

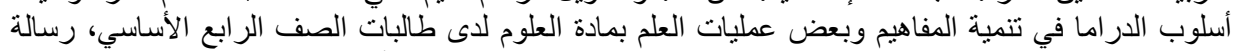

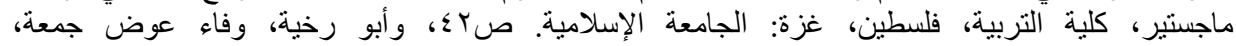

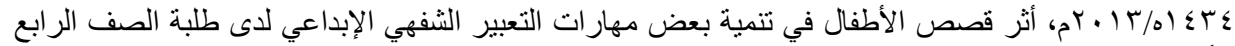

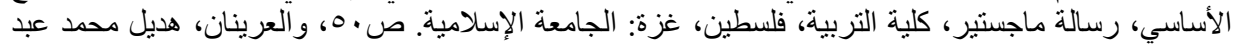

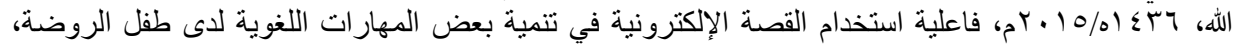

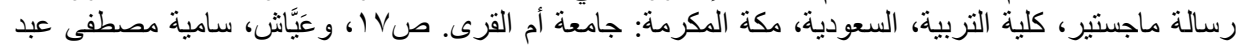

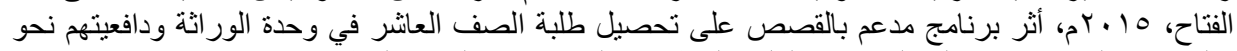

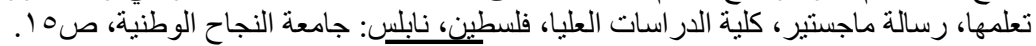


7- أن تزود التلميذ بالحقائق و المعارف والخبرات التي يحتاجون إليها في جوانب

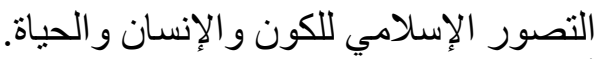

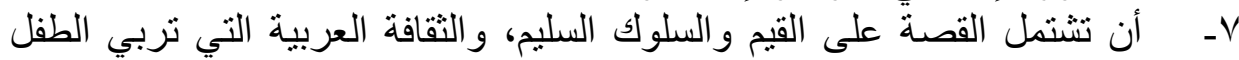

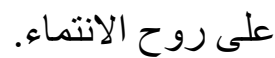
N- أن تتو افر فيها عناصر الإثارة والتشويق، كالجدة، و الطر افة، و الحركة.

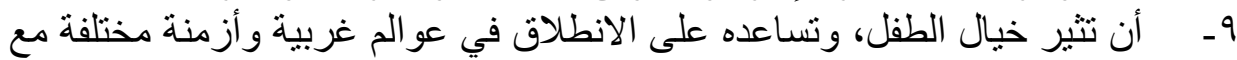

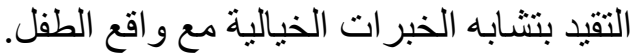

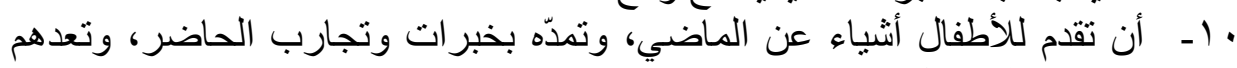

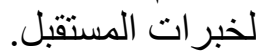

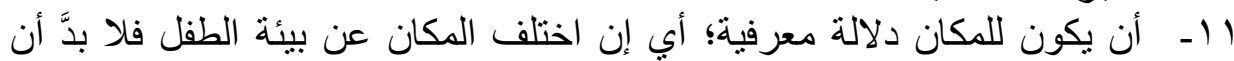

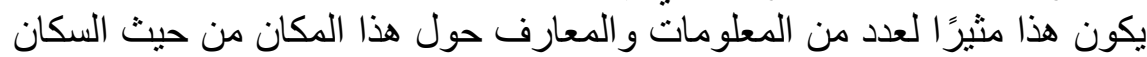

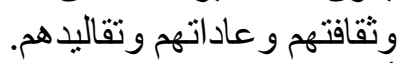

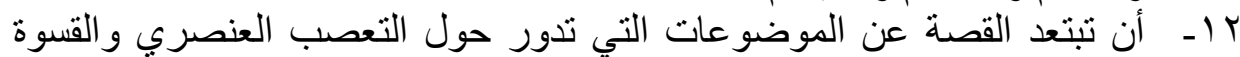

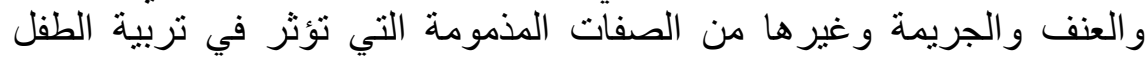
وتكوين ذوقه وخياله ولغته وغئه

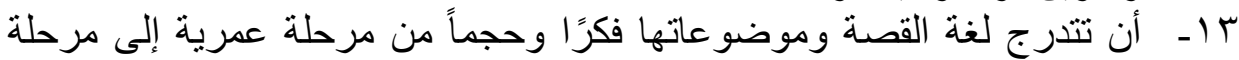

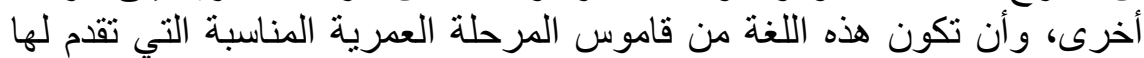
القصة.

ع ا ـ أن تخلو القصة من المحسنات البديعة الكثيرة، والأساليب المجازية المبالغ فيها

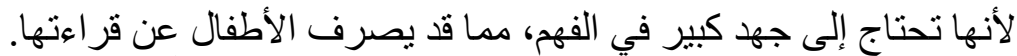

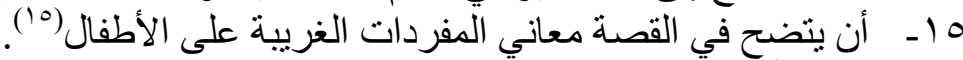

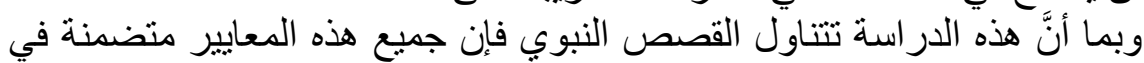

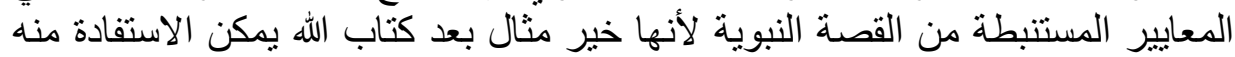
في إعداد معايير تربوية تعليمية ترتقي بالإنسان إلى المثل العليا التي تسعى التربية

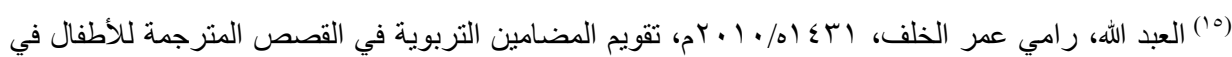

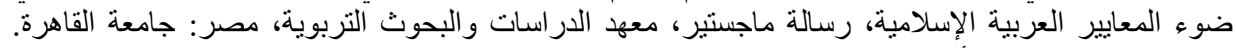

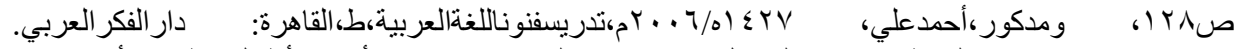

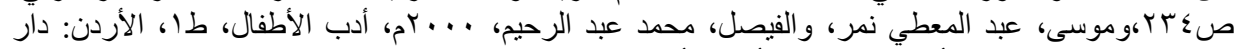

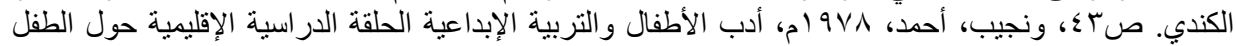

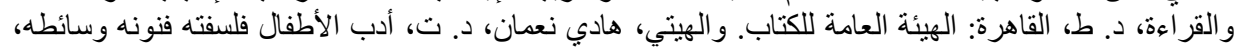

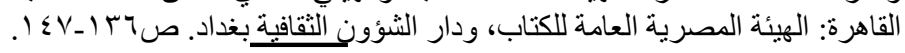


المعايير التربوية للقصة في السنة النبوية:

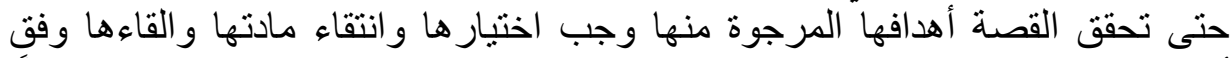

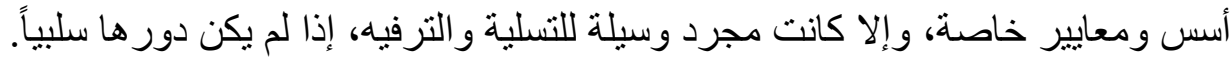

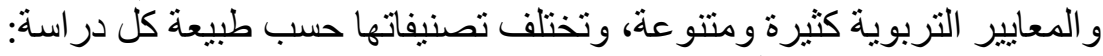

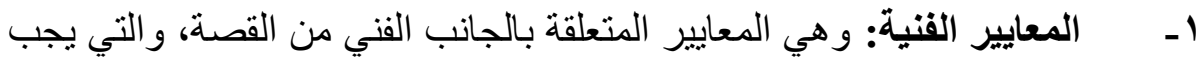

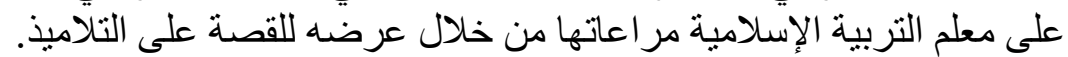

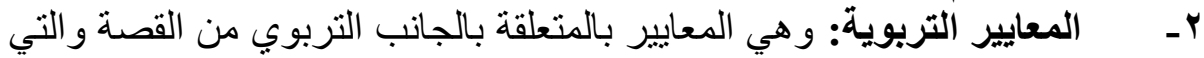

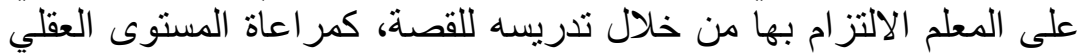
و العمري و البيئة الثقافية للتناميذ.

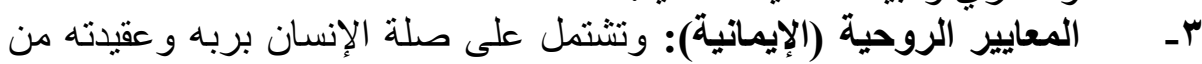

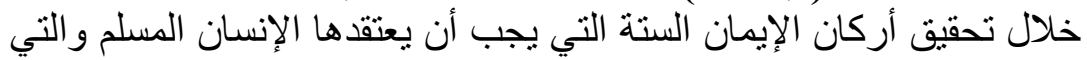

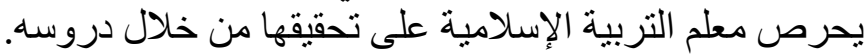

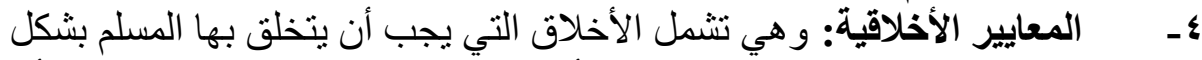

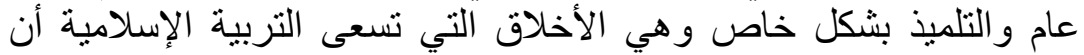

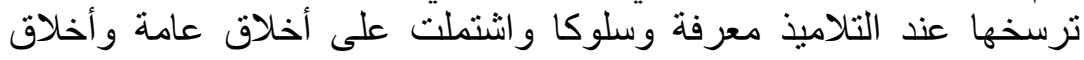
يجب التركيز عليها في مرحلة المر اهقة.

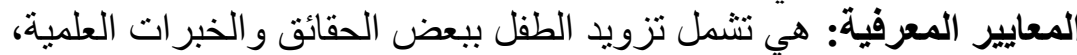

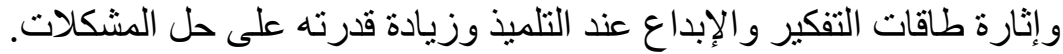

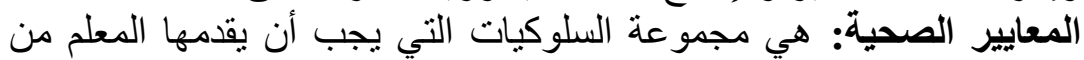

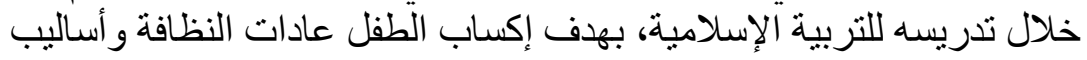

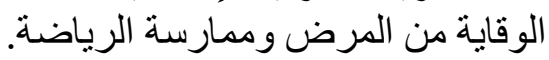

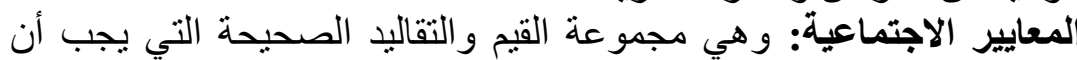
$-v$

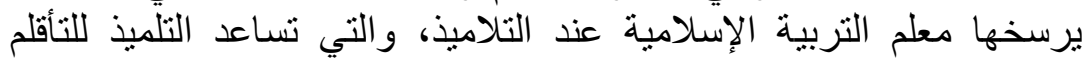

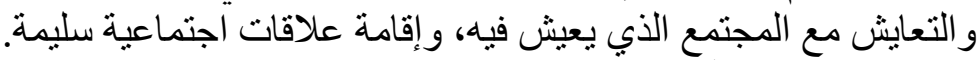
المعايير الاقتصادية: هي المعايير التي يسعى معلم التربية الإسلامية لتحقية لتحقيقها $-\Lambda$ من خلال تدريسه للتربية الإسلامية كالحث على العى العمل ونبذ التواكية التل وتثمير

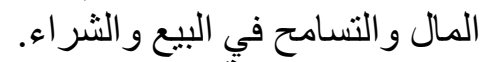
المعايير السياسية:ة: وهي المفاهيم والقيم السياسية التي يسعى معلم التربية

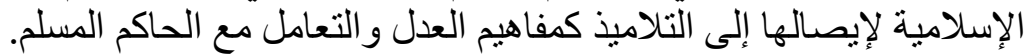
•- - المعايير البيئية: وهي القيم والسلوكيات التي يحاول معلم التربية الإسلامية

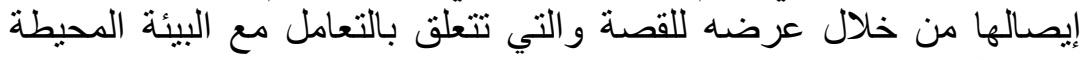
كالتعامل مع الحيو ان و النباتات الدحافظة على المياه. 
ثامنًا: منهج الاراسة: المنهج الوصفي التحليلي: اعتمدت الدراسة الحالية المنهج

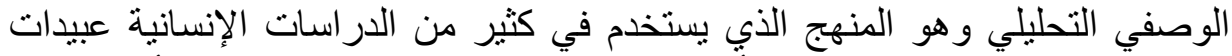

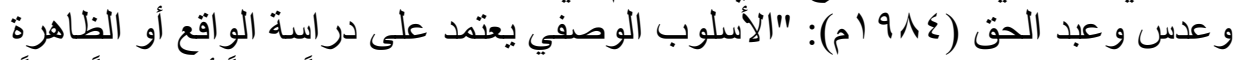

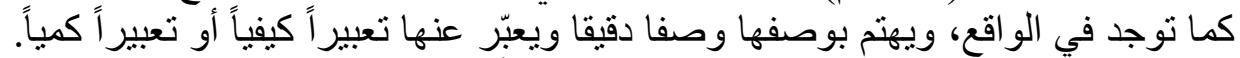

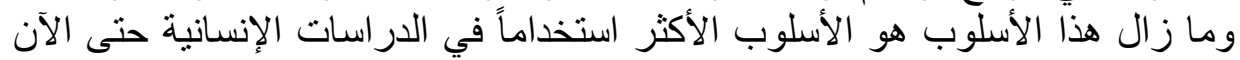

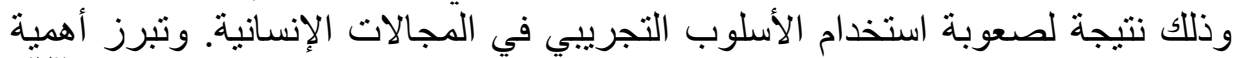

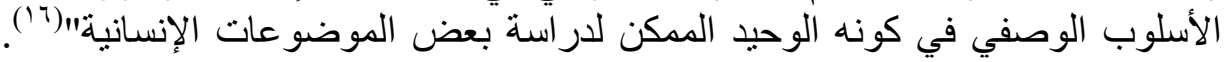
و هو ما تم تطبيقه في الدراسة. الاست.

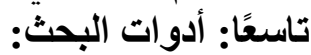
تمثلت الأدوات البحثية التي استخدمها البحث الحالي فيما يلي:

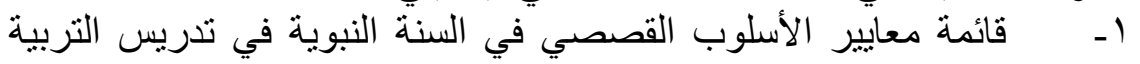

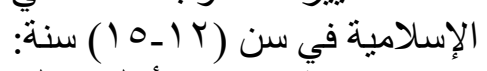

اعتمد الباحث في إعداد قائمة معايير الأسلوب القصصي في الإبه السنة على عدد من البحوث

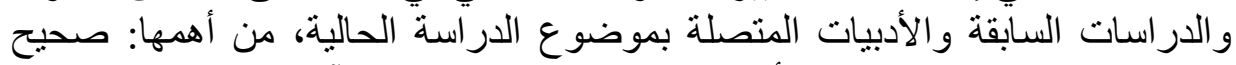

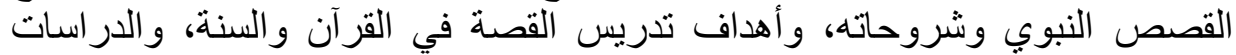
السابقة والأدبيات المتعلقة بتدريس التربية الإسلامية..

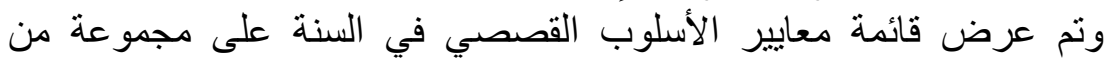

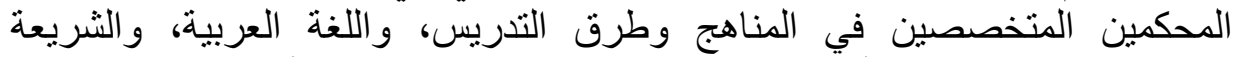

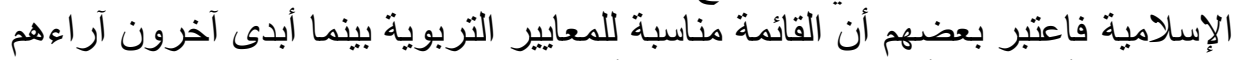

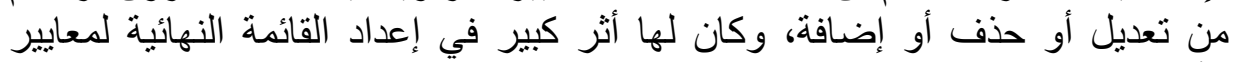

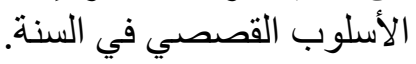

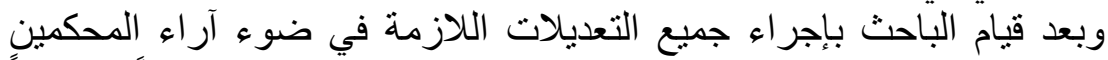

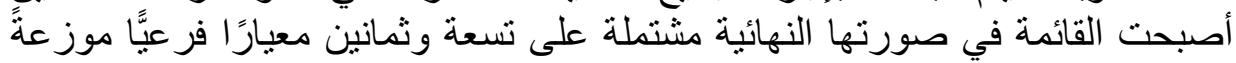
في عشرة معايير رئيسية وهي كما يلي:

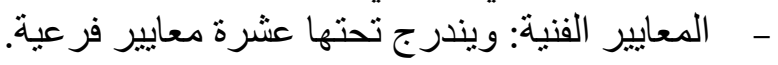
- - المعايير التربوية: ويندرج تحتها: عشرة معايير فرعية.

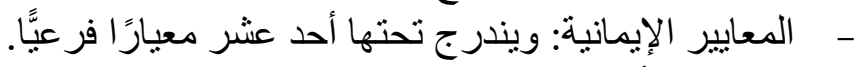

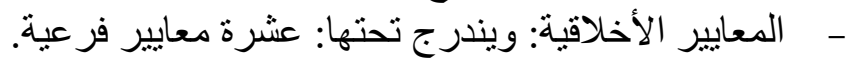

- - المعايير المعرفية: ويندرج تحتها: ثمانية معايير فرعية.

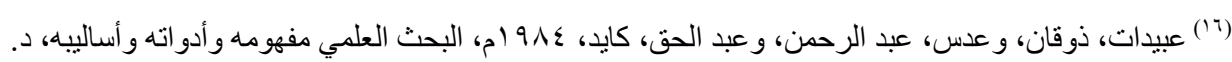

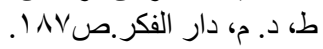


- المعايير الصحية: ويندرج تحتها: عشرة معايير فرعية. -

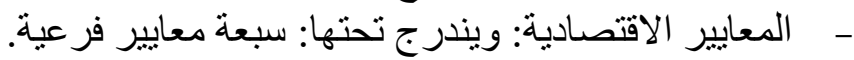

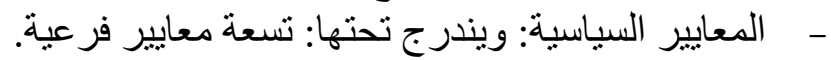

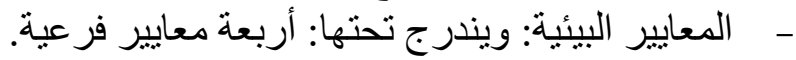

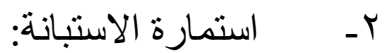

يستعمل عادة في مثل هذا النوع من الدراسات بطاقة الملاحظة لكونها الأكثر ملائمة

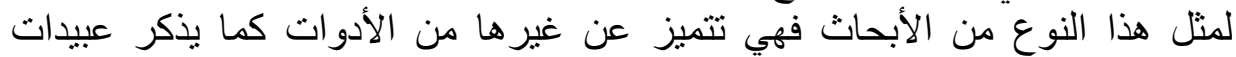

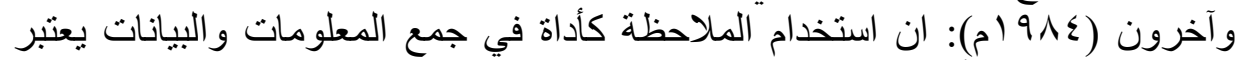

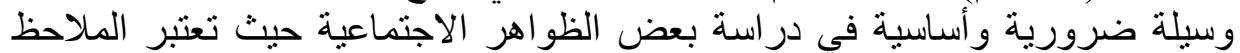

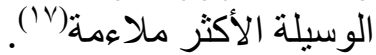

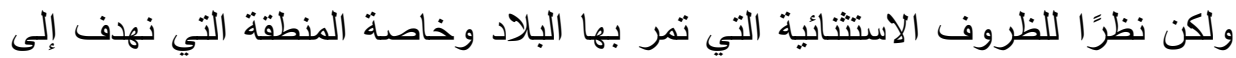

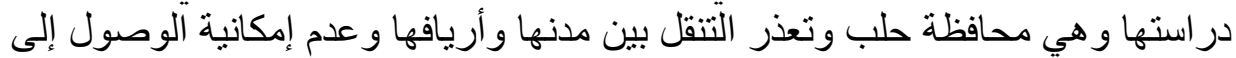

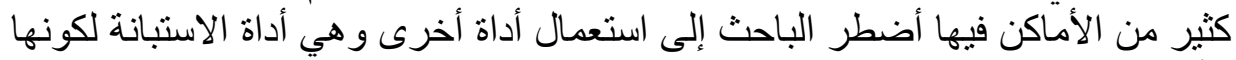

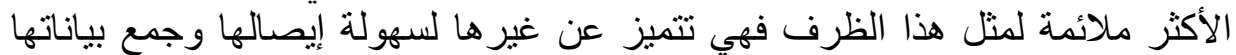

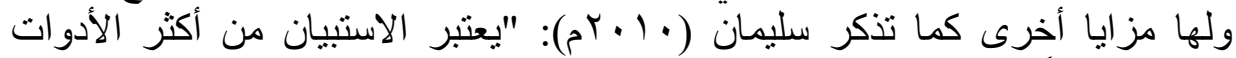

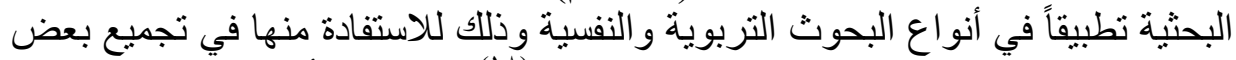

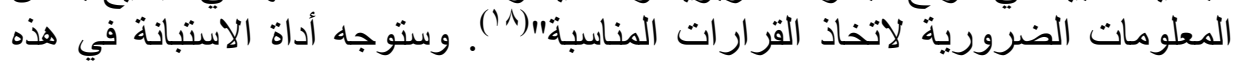

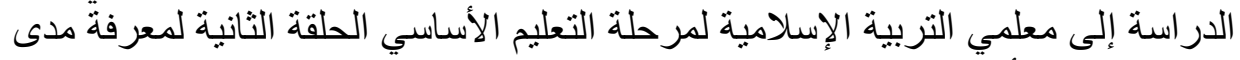

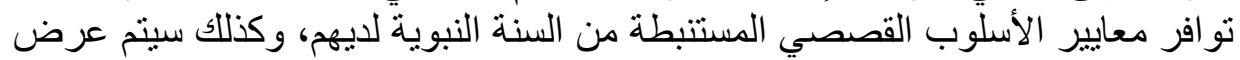

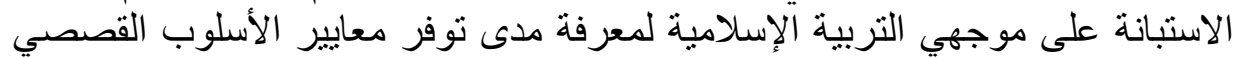

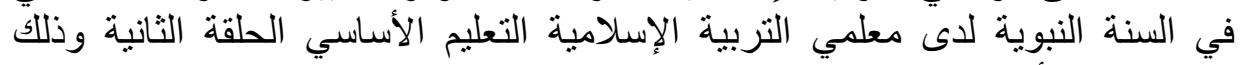

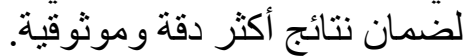

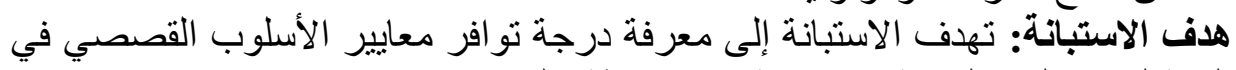

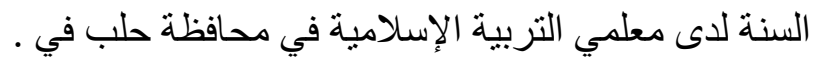

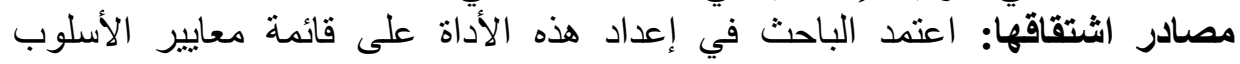

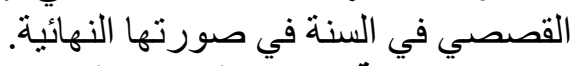
صدق الأستبانة: اعتمد الباحث على صدق القداتئ المحكمين الذين أقروا صلاحية قائمة معايير الأسلوب القصصي في السنة. البنة

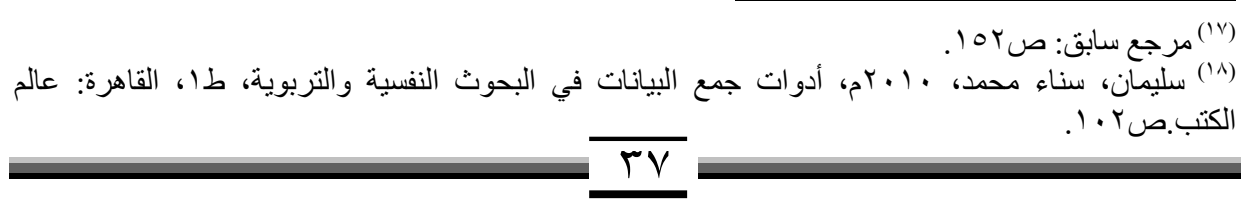


ثبات الاستبانة:يقول العبد و عزمي (ب99 (1)): "المقصود بالثبات: قياس مدى استقلالية

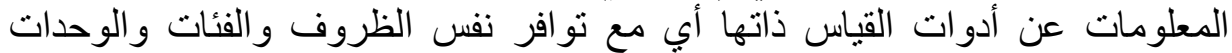

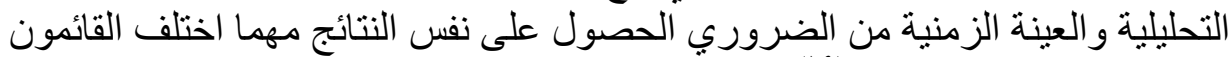

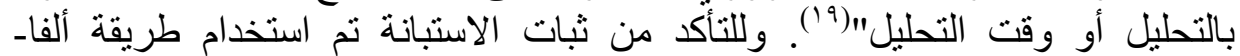

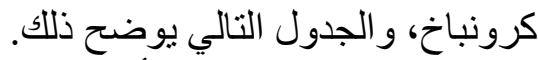
قيم معاملات الثبات بطريقة ألفا-كرونباخ التي ذون

\begin{tabular}{|c|c|}
\hline ألفا كرونباخ & المعايير \\
\hline$\cdot, \wedge \vee$. & المعايير الفنية \\
\hline$\cdot, \wedge 99$ & المعايير التربوية \\
\hline$\cdot, 9 \vee r$ & المعايير الإيمانية \\
\hline$\cdot, 901$ & المعايير الأخلاقية \\
\hline$\cdot, 9 \leq V$ & المعايير المعرفية \\
\hline$\cdot, 9 \leq 0$ & المعايير الصحية \\
\hline$\cdot, 9 Y 7$ & المعايير الاجتماعية \\
\hline$\cdot, 911$ & المعايير الاقتصادية \\
\hline$\cdot, 9 Y 0$ & المعايير السياسية \\
\hline$\cdot, 197$ & المعايير البيئية \\
\hline
\end{tabular}

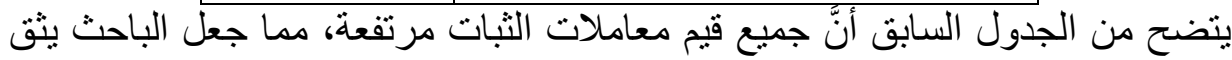

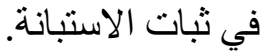
خطوات تطبيق الاستبانة: مرت الدر اسة بعدد من الخطبانة الخطوات الإجر ائية لتطبيق الاستبيان وهي كالتالي:

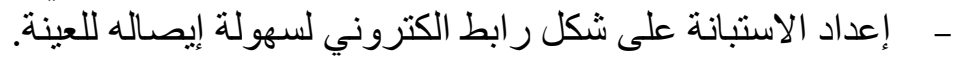

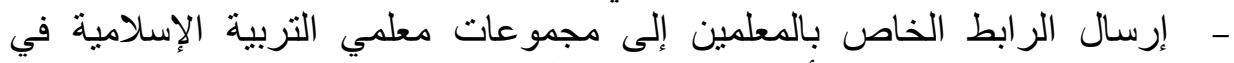
محافظة حلب وكذلك إلى أفر اد المعلمين بشكل خاص.

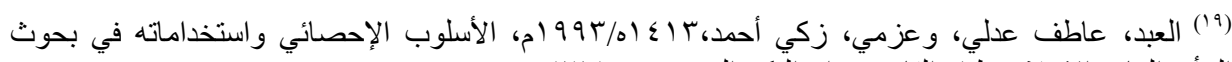

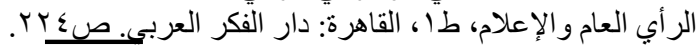


- - إرسال الر ابط الخاص بالموجهين إلى موجهي التربية الإسلامية في محافظة حلب

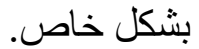

بقي الرابط معروضيًا لمدة عشرين يومًا. -

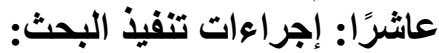

للإجابة عن السؤال الأول ما معايير الأسلوب القصصي في السُّنَّة قام الباحث

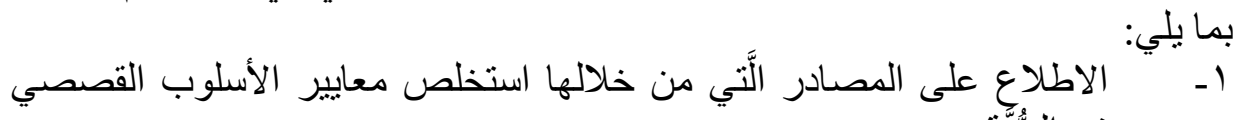
في السُّنَّة وهي: على العي: - - محيح القصص النَّويّ وشروحاته. -

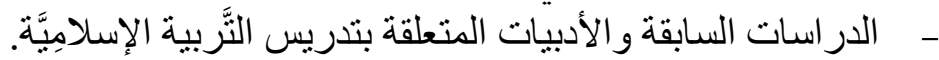

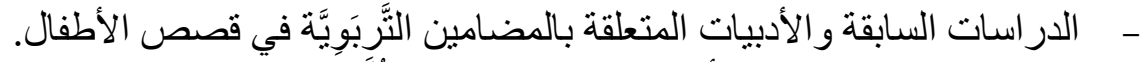

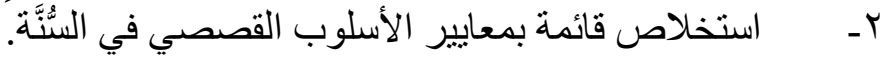

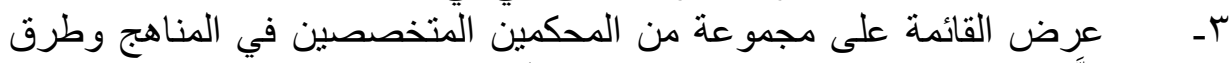

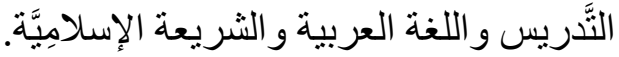
توصل إلى قائمة المعايير في شكلها النهائي.

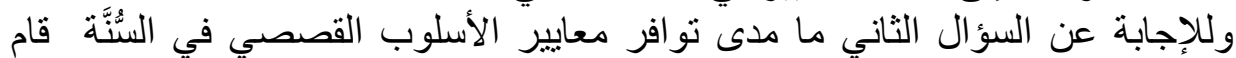

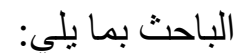

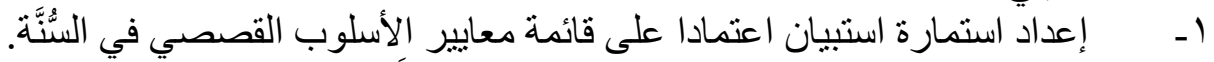

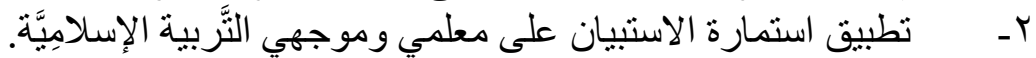

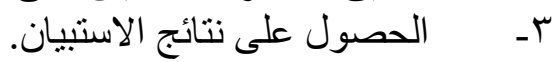

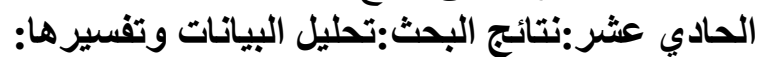

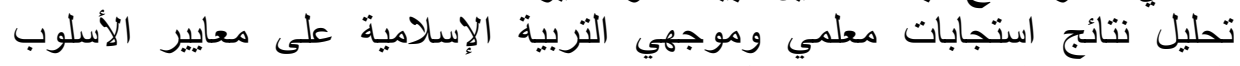

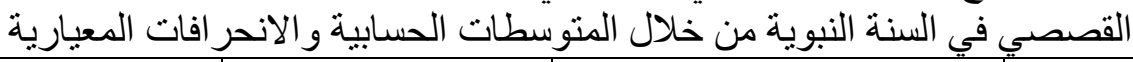

\begin{tabular}{|c|c|c|c|c|c|}
\hline \multicolumn{2}{|c|}{ استمارة الموجهين } & \multicolumn{2}{|c|}{ استمارة المعلمين } & \multirow[b]{2}{*}{ المعايير الفرعية } & \multirow[b]{2}{*}{ ترتيب } \\
\hline الانحراف & الحتوسطي & الانحياري & الحستوسط & & \\
\hline$\cdot, 10$ & $r, \varepsilon$ & $1, \cdot r$ & $r, \varepsilon \varepsilon$ & المعايير الفنية & 1 \\
\hline$\cdot, \vee \wedge$ & $r, V I$ & $\cdot, 99$ & $r, 07$ & المعايير التربوية & $r$ \\
\hline$\cdot, \vee \vee q$ & $r, v q$ & $1,1 \leqslant$ & $\Gamma, \wedge 0$ & المعايير الإيمانية & r \\
\hline$\cdot, \wedge \wedge$ & $r, 74$ & $1, \cdot 7$ & $r, V \wedge$ & المعايير الأخلاقية & $\varepsilon$ \\
\hline
\end{tabular}




\begin{tabular}{|c|c|c|c|c|c|}
\hline$\cdot, \wedge 7$ & $r, \Lambda$ & 1,14 & $r, 17$ & المعايير المعرفية & 0 \\
\hline$\cdot, 19$ & q & 1,17 & ס ז, & المعابير الصحية & 7 \\
\hline$\cdot, \wedge$. & $r, 70$ & $1, \cdot \varepsilon$ & $r, 7 \varepsilon$ & المعايير الاجتماعية & V \\
\hline$\cdot, 91$ & $r, v$ & 1,19 & r, $\varepsilon$. & المعايير الاقتصادية & $\Lambda$ \\
\hline $1,1$. & $\Gamma, Y \wedge$ & ו. & דr, & المعايير السياسية & 9 \\
\hline - , Vᄉ & $r, 0$ & $1, Y Y$ & r,or & المعايير بيئية & 1 . \\
\hline$\cdot, 9$. & $\Gamma, \varepsilon \wedge$ & $1,1 r$ & $\Gamma, 01$ & المتوسط العام & 11 \\
\hline
\end{tabular}

يتبين من معطيات الجدول السابق أن المتوسط الكلي لمعايير الأسلوب

القصصي في السنة من خلال استجابة المعلمين جاء بمنوسط حسابي بلغ (1,01)

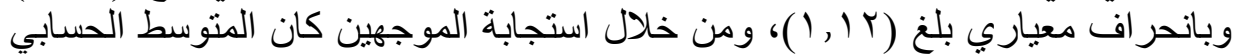

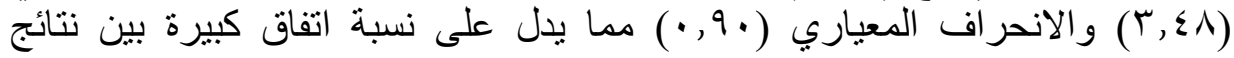

وأن المعايير الإيمانية كانت في أعلى معدل ويعزى السبب لاهتمام معلمي

التربية الإسلامية للجوانب الإيمانية في تدريسهم للتربية الإسلامية في استجابة المعلمين

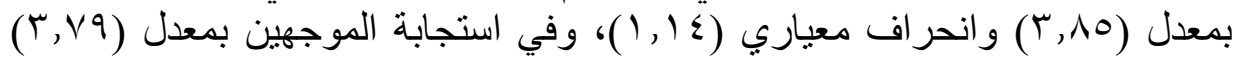

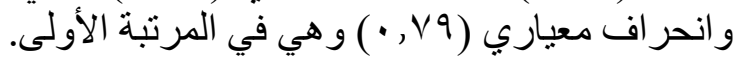

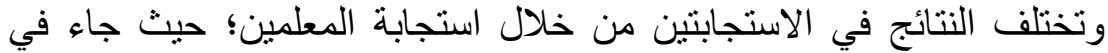
المرتبة الثانية المعايير الأخلافية حيث يوجد اهتمام واضح لافى معلمي التربية الإسلامية

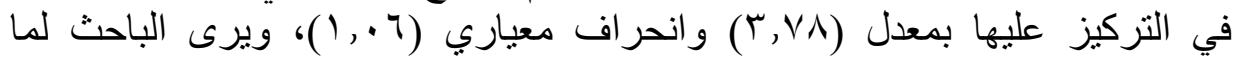
لمرحلة التعليم الأساسي الحلقة الثانية من خصوصية فهي تو افق مرحلة المر اهقة وهي تتطلب تركيز كبير على الجانب الأخلافي، وتأتي في المرتبة الثالثة المعايير الاجتماعية

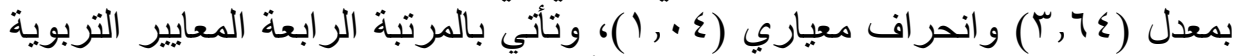

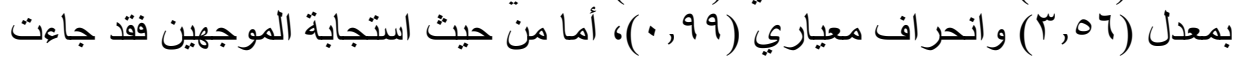

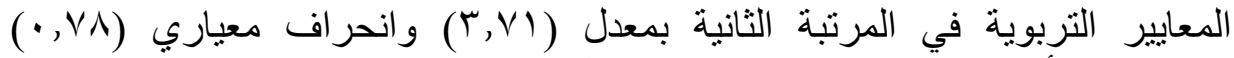

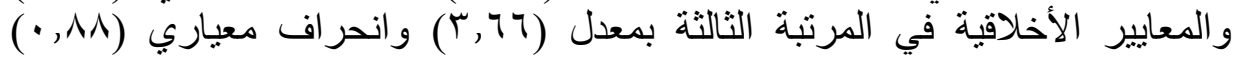

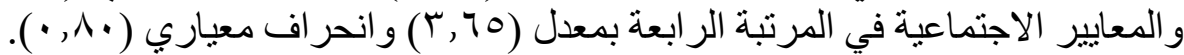
وتتفق الاستجابتان في المرتبة الخامسة المعايير البيئية عند المعلمين بمعدل

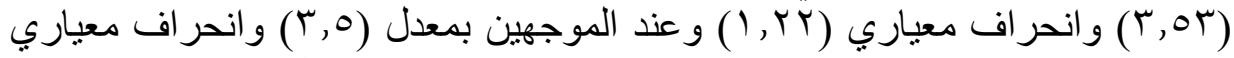

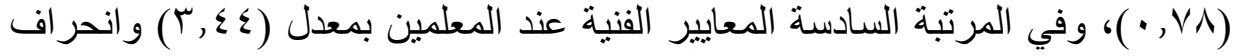

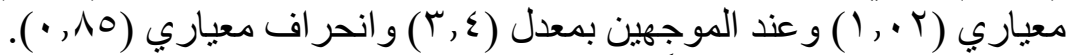

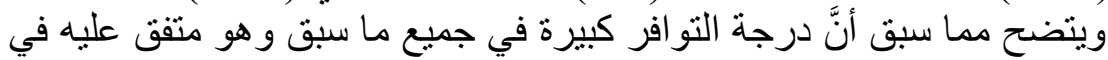


وتختلف الاستجابة في المرتبة السابعة فعند المعلمين المعايير الاقتصادية بمعدل

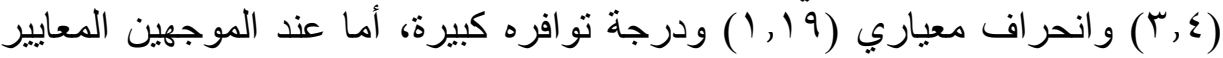

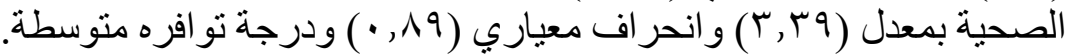

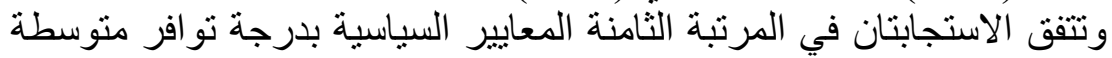

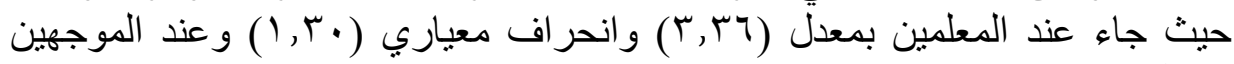

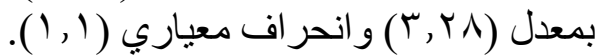
وتختلف الاستجابة كذللك فعند المعلمين في المرتبة المبان التاسعة المعايير الصحية

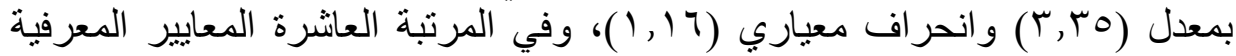

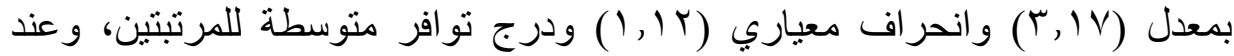

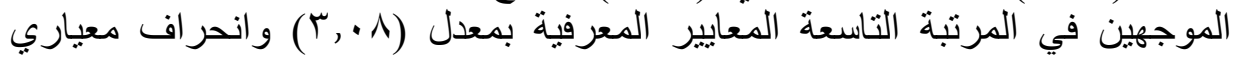

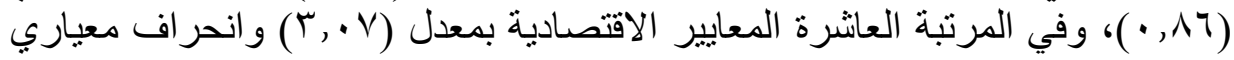

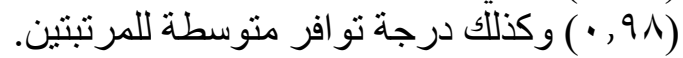

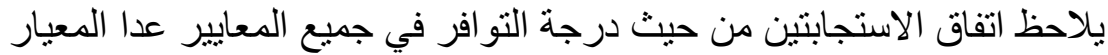

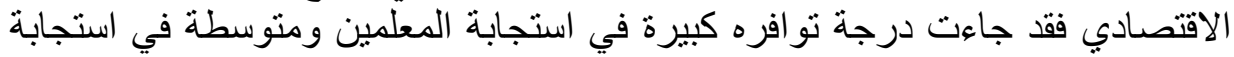

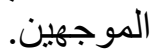




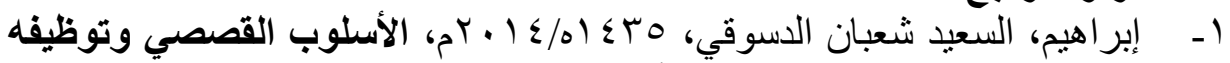

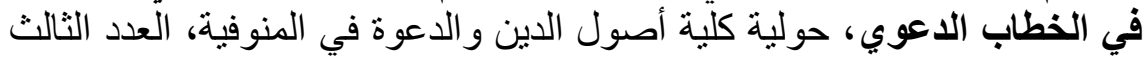

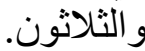

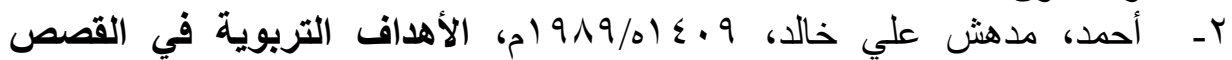

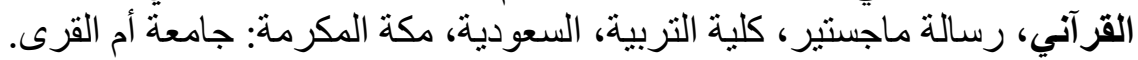

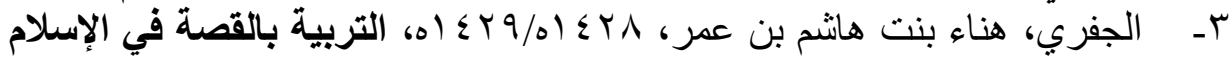

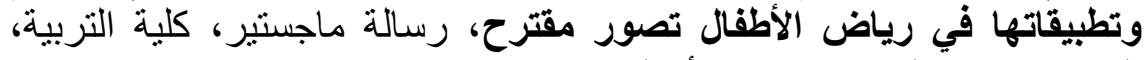

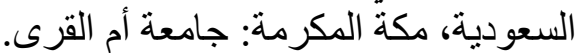

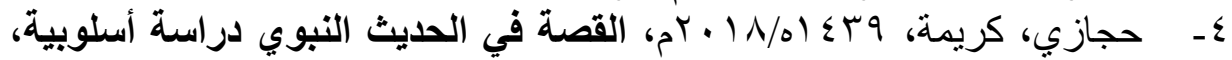

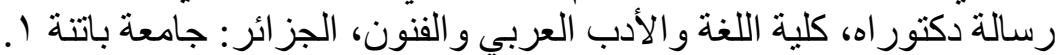

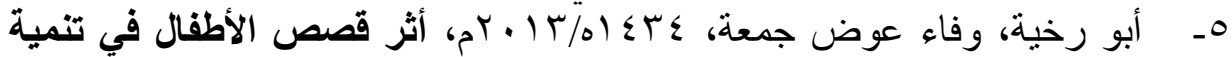

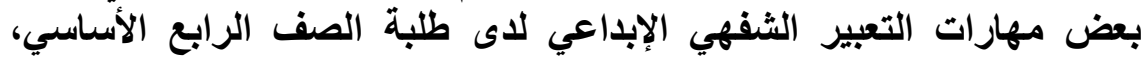

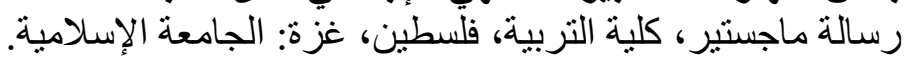

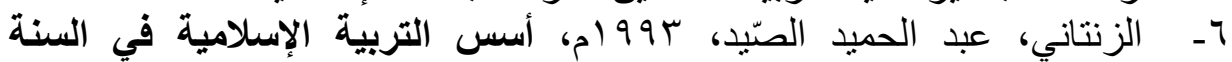

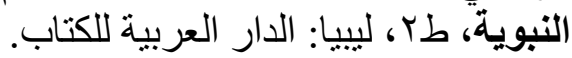

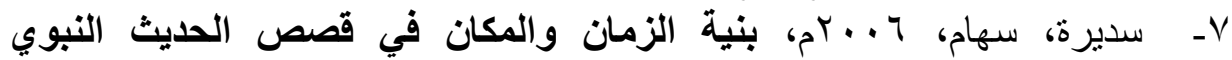

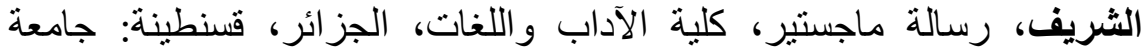

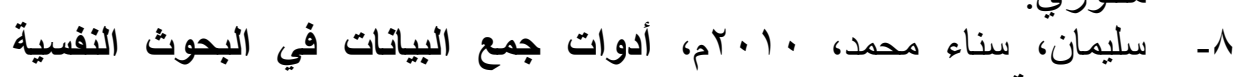

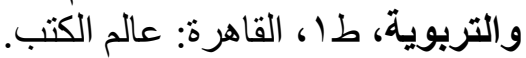

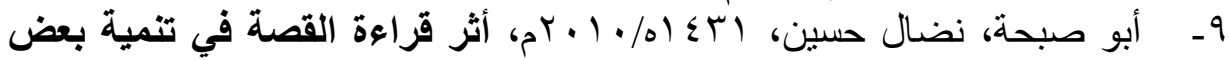
مهارات التعبير الكتابي لاى طالبات الصف التاسع الأساسي، رسالة ماجستير ، التانة

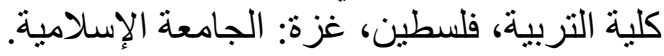

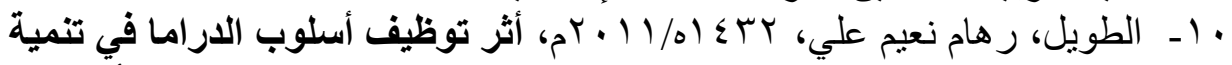

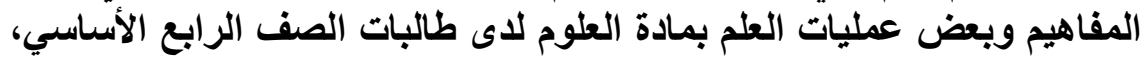

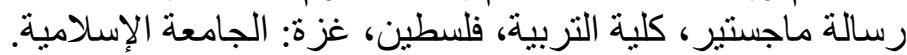

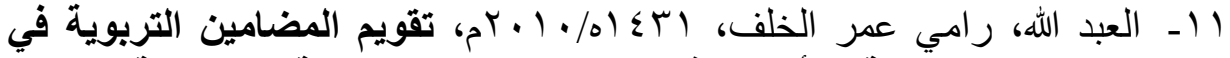

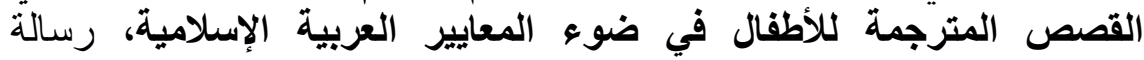

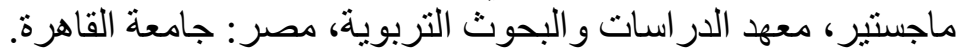

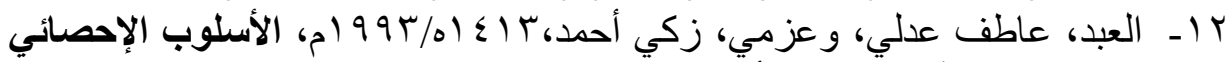
واستخذاماته في بحوث الرأي العام والإعلام، طا ، القاهرة: دار الفكر العربي. 


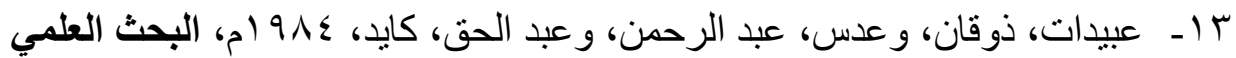

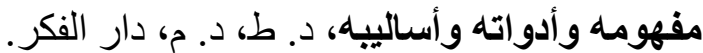

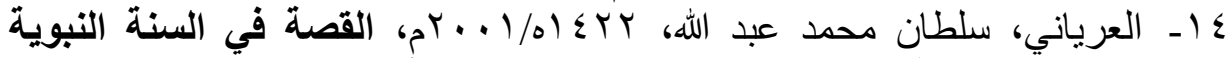

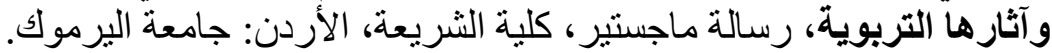

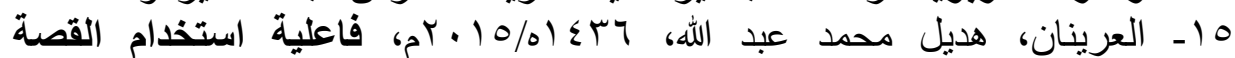

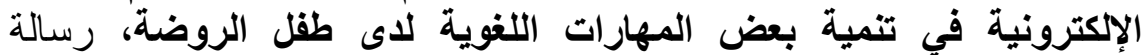

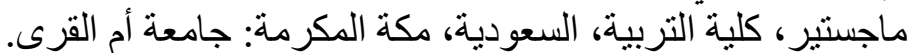

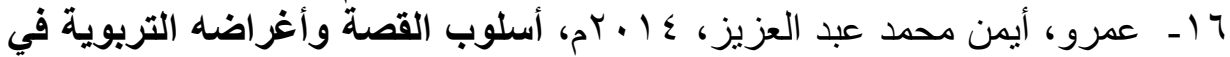

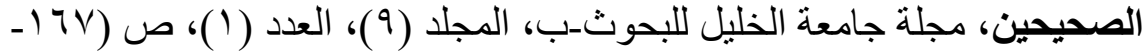
( ( ) 199 IV

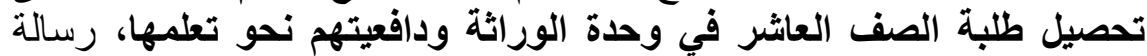

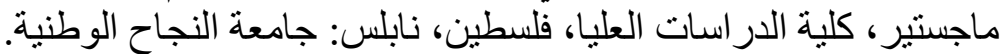

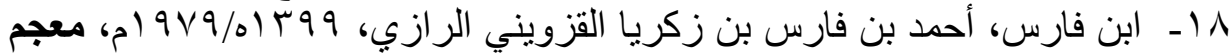

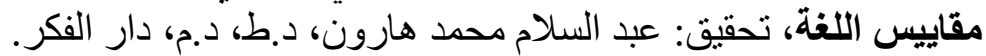

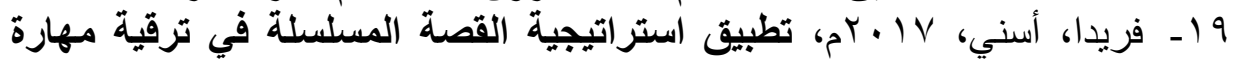

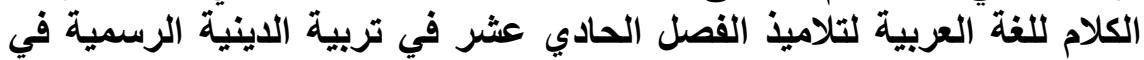

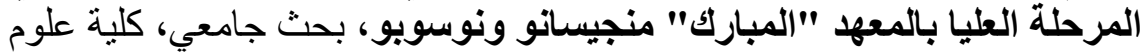

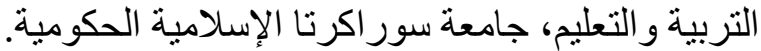

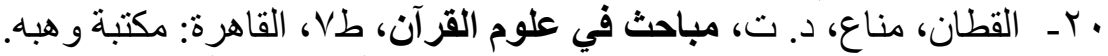

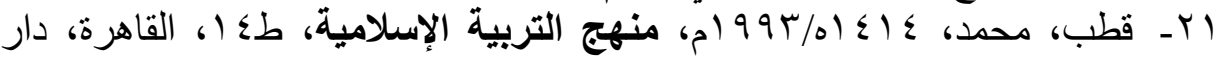

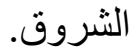

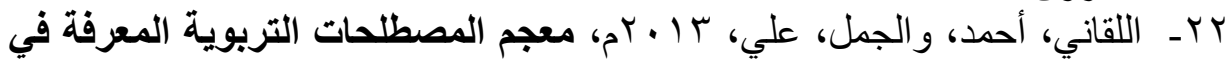

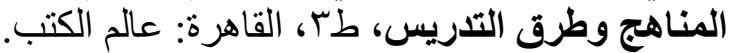

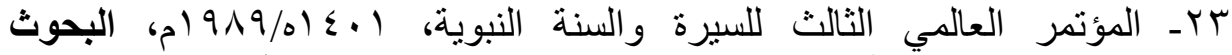

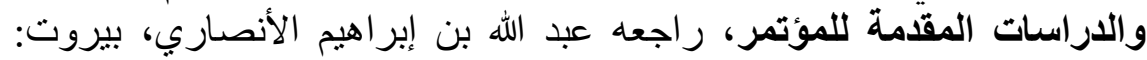
المكتبة العصرية.

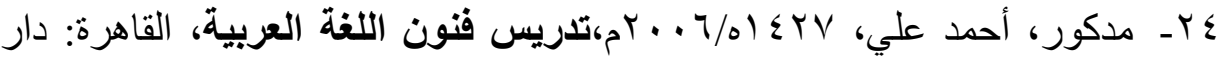

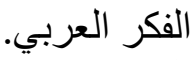

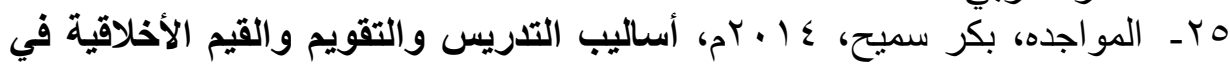

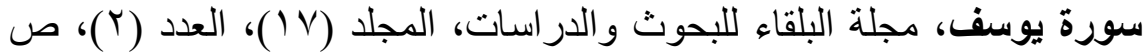
( (1) 


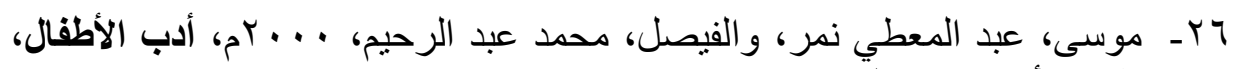
طا، الأردن: دار الكندي.

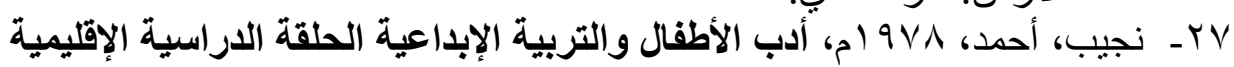

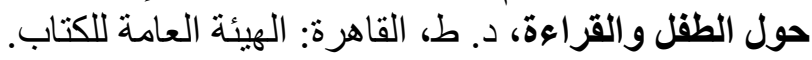

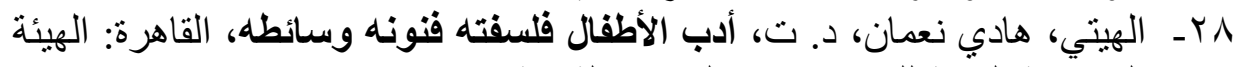

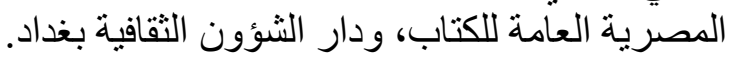

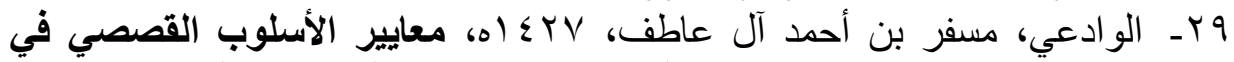

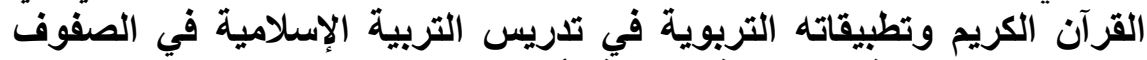

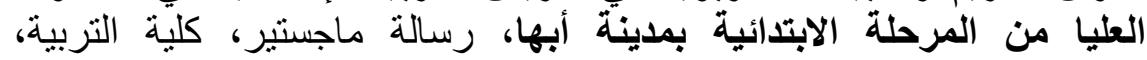
السعودية، مكة المكرمة: جامعة أم القرى. 